\title{
Differential Transcriptional Profiles of Dormancy-Related Genes in Apple Buds
}

\author{
Vítor da Silveira Falavigna • Diogo Denardi Porto • \\ Vanessa Buffon • Márcia Margis-Pinheiro • \\ Giancarlo Pasquali • Luís Fernando Revers
}

Published online: 28 November 2013

(C) Springer Science+Business Media New York 2013

\begin{abstract}
The production of temperate fruit crops depends on plant developmental processes, primarily the shift from the juvenile phase to the reproductive phase, dormancy transitions and flowering. Apple tree (Malus $\times$ domestica Borkh.) development is regulated by chilling temperatures, which are required for bud dormancy progression. The apple cultivar Castel Gala is a spontaneous mutation of "Gala Standard". "Castel Gala" is characterized by a $50 \%$ decrease in the chilling requirement (CR) for dormancy release, which results in an earlier budbreak. This work explores the contrasting phenotypes of these cultivars using suppression subtractive hybridization (SSH). From 1,019 unigenes identified by SSH, we selected 28 candidate genes putatively associated with dormancy cycling. Reverse transcription-quantitative polymerase chain reaction was used to validate the differential expression profiles and to transcriptionally characterize these genes in three distinct apple cultivars ("Castel Gala", "Royal Gala" and "Fuji Standard") during a cycle comprising growth to dormancy. Of the 28 candidate genes analyzed, 17
\end{abstract}

The nucleotide sequences reported in this paper have been submitted to GenBank with the accession numbers JZ480898 to JZ482228.

V. S. Falavigna and D. D. Porto contributed equally to this work.

Electronic supplementary material The online version of this article (doi:10.1007/s11105-013-0690-0) contains supplementary material, which is available to authorized users.

V. d. S. Falavigna $\cdot$ M. Margis-Pinheiro $\cdot$ G. Pasquali

Graduate Program in Cell and Molecular Biology, Centro de

Biotecnologia, Universidade Federal do Rio Grande do Sul, Porto

Alegre, RS 91501-970, Brazil

D. D. Porto $•$ V. Buffon • L. F. Revers $(\bowtie)$

Laboratory of Plant Molecular Genetics, Centro Nacional de

Pesquisa de Uva e Vinho, Empresa Brasileira de Pesquisa

Agropecuária, Rua Livramento, 515, P.O. Box 130, CEP

95700-000 Bento Gonçalves, RS, Brazil

e-mail: luis.revers@embrapa.br confirmed the differences in expression predicted by SSH. Seasonal transcript accumulation during the winter was observed for several genes, with higher steady-state mRNA levels maintained longer in cultivars with a high CR. The transcription profiles suggest that these genes may be associated with dormancy establishment and maintenance. Of the 17 candidate genes, transcripts coding for dormancy-associated MADS-box (DAM), dehydrins, GAST1, LTI65, NAC, HTA8, HTA12 and RAP2.12-like proteins displayed major differences in gene expression between cultivars through the winter. These genes were therefore considered good candidates for key roles in the dormancy process in apple trees.

Keywords Apple · Bud dormancy · Gene expression · Malus $\times$ domestica $\cdot$ RT-qPCR $\cdot$ Suppression subtractive hybridization

$\begin{array}{ll}\text { Abbreviations } \\ \text { ABA } & \text { Abscisic acid } \\ \text { AP2 } & \text { APETALA2 } \\ \text { ARC5 } & \text { Accumulation and replication of chloroplast 5 } \\ \text { ARP6 } & \text { Actin-related protein 6 } \\ \text { CAMTA1 } & \text { Calmodulin-binding transcription activator 1 } \\ \text { CBF } & \text { C-repeat binding factor } \\ \text { CO } & \text { CONSTANS } \\ \text { COR } & \text { Cold-regulated } \\ \text { CR } & \text { Chilling requirement } \\ \text { CRT } & \text { C-repeat } \\ \text { DAM } & \text { Dormancy-associated MADS-box } \\ \text { DHN } & \text { Dehydrin } \\ \text { DRE } & \text { Dehydration-responsive element } \\ \text { DREB } & \text { Dehydration-responsive element binding protein } \\ \text { EST } & \text { Expressed sequence tag } \\ \text { FT } & \text { FLOWERING LOCUS T } \\ \text { GAST1 } & \text { GA stimulated transcript 1 } \\ \text { GO } & \text { Gene ontology }\end{array}$




\begin{tabular}{|c|c|}
\hline GolS & Galactinol synthase \\
\hline GRAS & GA insensitive, repressor of GA1, scarecrow \\
\hline ICE1 & Inducer of CBF expression 1 \\
\hline LEA & Late embryogenesis abundant \\
\hline LOS1 & $\begin{array}{l}\text { Low expression of osmotically } \\
\text { responsive genes } 1\end{array}$ \\
\hline LTI & Low-temperature inducible \\
\hline LTI65 & Low-temperature-induced 65 \\
\hline $\mathrm{MDH}$ & Malate dehydrogenase \\
\hline NAC & No apical meristem \\
\hline ATAF1/2 & Cup-shaped cotyledon 2 \\
\hline RAP2.12 & Related to APETALA2-12 \\
\hline $\mathrm{RCI}$ & Rare cold inducible gene \\
\hline RT-qPCR & $\begin{array}{l}\text { Reverse transcription-quantitative } \\
\text { polymerase chain reaction }\end{array}$ \\
\hline SCL & Scarecrow-like \\
\hline SD & Short days \\
\hline SSH & Suppression subtractive hybridization \\
\hline WD40 & $\begin{array}{l}\text { Transcription factor WD40-like } \\
\text { repeat domain }\end{array}$ \\
\hline
\end{tabular}

\section{Introduction}

Perennial woody plants from temperate climate regions, such as apples (Malus $\times$ domestica Borkh.), undergo a dormancy process characterized by the cessation of visible growth (Horvath et al. 2003; Rohde and Bhalerao 2007). Dormancy is an adaptive mechanism for plant survival in temporarily unsuitable environments, and a well-adjusted dormancy cycle is a determinant for the plant to achieve its full genetic potential. Bud dormancy is conceptually divided into three different types according to the growth inhibition mechanism: endodormancy, when inhibitory signals reside inside the bud itself; paradormancy, in which buds are prevented from growing due to signals produced in distal parts of the plant; and ecodormancy, when harsh environmental conditions prevent bud growth (Lang et al. 1987). In this work, the term dormancy is used to refer to endodormancy.

Dormancy is triggered by adverse environmental conditions, such as exposure to low temperatures and photoperiodic modifications (Horvath et al. 2003; Rohde and Bhalerao 2007). Entrance into dormancy, especially when induced by short days (SD), is quite well characterized. In Arabidopsis thaliana, CONSTANS (CO) and FLOWERING LOCUS T (FT) are proteins that are responsible for day length perception and flowering, respectively. In aspen trees, the $\mathrm{CO} / \mathrm{FT}$ module also regulates dormancy establishment (Böhlenius et al. 2006). In poplars, dormancy entrance requires transcriptional and metabolic reprogramming, directing cellular resources towards the synthesis of osmoprotectors and cold acclimation-related proteins, primarily orchestrated by abscisic acid (ABA) and ethylene (Ruttink et al. 2007). These hormones participate in bud set and dormancy entrance because ethylene-insensitive birches do not form terminal buds and have abnormal ABA production (Ruonala et al. 2006). In peaches, a family of dormancy-associated MADS-box genes (DAM) is required for growth cessation and dormancy establishment (Bielenberg et al. 2008). Molecular models for dormancy control based on photoperiodic changes and temperature perception have been proposed and reviewed (Horvath 2009; Campoy et al. 2011). In these models, SD and short-term exposure to low temperatures induce dormancy through phytochrome and C-repeat binding factor (CBF) signaling by regulating the $\mathrm{CO} / \mathrm{FT}$ module and $D A M$ gene expression, respectively (Böhlenius et al. 2006; Horvath 2009).

Dormancy release and cold perception, the latter being central in dormancy progression, are still poorly understood processes at the molecular level in plants. Overcoming bud dormancy requires exposure to extended periods of cold temperatures. Fulfillment of this chilling requirement (CR) leaves the bud in an ecodormant state, and the amount of the CR is species- and/or cultivar-dependent, suggesting a strong genetic control of this trait (Dennis 1987; Howe et al. 2000; Labuschagné et al. 2002). Cold exposure can be replaced by gibberellin application, and in fact, several genes of the gibberellin biosynthesis pathway are induced by cold (van der Schoot and Rinne 2011). According to Horvath (2009), coldinduced chromatin remodeling processes at different loci might also participate in the regulation of genes during bud dormancy establishment and release.

Because dormancy release depends on CR fulfillment, it is often difficult to obtain high crop yields from temperate fruit crops grown in mild-winter climates. Success in such production systems requires the use of chemical or other means to break bud dormancy to compensate for insufficient chilling. Models of future global climate conditions predict the rising of global mean temperatures and milder winters, which could compromise temperate crop yields in future decades (Campoy et al. 2011). The development of cultivars with low CRs is a promising alternative to sustain crop production in a changing environment. Therefore, understanding the mechanisms responsible for this phenotype may permit the development of new strategies to reach this goal.

Apple bud dormancy regulation differs from better-studied dormancy models, such as poplar and peach, because it is triggered by low temperature exposure, regardless of photoperiodic conditions (Heide and Prestrud 2005). Dormancy in apple buds is well characterized physiologically (Faust et al. 1997). Recently, a major quantitative trait locus for flowering time and vegetative bud break, an agronomical feature associated with CR, has been found in a segment at the distal region of chromosome 9 enriched with cell-cycle related genes (van Dyk et al. 2010; Celton et al. 2011). In spite of these advances, little transcriptional information is available 
for dormancy control in apple buds (Troggio et al. 2012). The pioneering work published by Pichler et al. (2007) reported variability in gene expression in summer and autumn samples of apple spur buds as assessed by microarray analysis. That study showed that the induction of dormancy was responsible for up- and down-regulation of a large number of genes, but in-depth classification, annotation and in silico characterization of these genes was not reported.

New apple tree cultivars usually arise from spontaneous bud sport mutations, which are clonally propagated and tested for phenotype stability. This is the case for "Royal Gala", which is a color mutation of "Gala Standard" largely cultivated around the world. Apart from fruit color differences, these cultivars have identical traits, including patterns of bud dormancy and CRs (Walsh and Volz 1990; EPAGRI 2006). The Castel Gala cultivar, which also originated from a spontaneous bud sport mutation of a "Gala Standard" apple tree, features a low $\mathrm{CR}-300 \mathrm{~h}$ - when compared to the original cultivar $600 \mathrm{~h}$ (Denardi and Seccon 2005; Anzanello 2012). This new cultivar exhibits a precocious growth cycle that starts 25 days earlier than "Gala Standard", while producing fruits that are anatomically and nutritionally equivalent (Denardi and Seccon 2005).

The release of the apple genome (Velasco et al. 2010), the available apple EST databases with over 300,000 sequences, and new annotation tools provide good frameworks for better exploration of high-throughput apple genomics data. This combination of resources prompted us to explore the model "Gala Standard" versus "Castel Gala" to obtain transcriptional information on apple bud dormancy regulation. In this work, the suppression subtractive hybridization ( $\mathrm{SSH}$ ) technique was used to perform a differential gene expression study in closed terminal buds of Gala Standard and Castel Gala cultivars, with the aim of identifying genes involved in dormancy establishment, maintenance and release. Four SSH libraries were constructed and the steady-state mRNA levels of 28 putatively differentially expressed genes were analyzed by reverse transcription-quantitative polymerase chain reaction (RT-qPCR) for validation. We quantified transcript accumulation for 17 validated genes at diverse time points during years 2009 and 2010 for three different CR cultivars. We identified for the first time several genes related to apple bud dormancy. The results gathered from the expression analyses of these genes are presented and discussed in the light of current models of dormancy establishment and progression.

\section{Materials and Methods}

\section{Plant Material}

All samples consisted of fully closed terminal buds of apple (Malus $\times$ domestica Borkh.) at the phenological stage "A" according to the Fleckinger scale (EPPO 1984). Closed terminal buds were harvested from apple trees located in three different experimental areas of Santa Catarina State, Brazil (Fig. 1). The climate in the three locations has well-defined seasons, evenly distributed rainfall throughout the year, and cold winters. Harvested material was immediately frozen in liquid nitrogen until storage at $-80{ }^{\circ} \mathrm{C}$.

Bud samples for the SSH procedure were taken in the commercial orchard where the Castel Gala cultivar was first identified (city of Monte Castelo, 26 $37^{\circ} 39^{\prime \prime}$ S, 50 $10^{\circ} 7.73^{\prime \prime}$ W and $791 \mathrm{~m}$ altitude). The samples consisted of closed terminal buds from six "Castel Gala" and two "Gala Standard" trees. These six "Castel Gala" individuals are the starting genetic material of this cultivar. The trees were grafted on Marubakaido rootstock in 2001. Closed terminal buds (3550 each plant) from both cultivars were harvested on May 29 and August 13, 2007. Total RNAs isolated from these samples were used to construct the SSH library (Fig. 1) and in the RTqPCR assays. Closed terminal buds from the same trees were also sampled on May 29 and July 29, 2008 for RT-qPCR analysis.

The transcripts that were identified and validated as differentially expressed were analyzed in a new set of closed terminal buds. The samples consisted of three biological replicates, each containing 20 "Castel Gala" or "Royal Gala" plants located at a commercial orchard in the city of Papanduva $\left(26^{\circ} 26^{\prime} 68^{\prime \prime} \mathrm{S}, 50^{\circ} 5^{\prime} 47^{\prime \prime} \mathrm{W}\right.$ and 788 $\mathrm{m}$ altitude). "Castel Gala" plants were grafted on M.9 rootstocks in 2006. "Royal Gala" trees were grafted on Marubakaido rootstocks with M.9 as the interstock in 2003. Five closed terminal buds from each tree were sampled at six different time points from May 2009 to April 2010 (Fig. 1). Harvesting dates and corresponding chilling hours $\left(<7.2{ }^{\circ} \mathrm{C}\right)$ recorded during the $2009 / 2010$ growing cycle are depicted in Table S1. RNAs extracted from all bud samples were used in RT-qPCR studies.

The commercial orchards are subjected to standard management practices for apple production in subtropical climates, including the application of the dormancy breaking agent hydrogen cyanamide (which was conducted after sampling). In an attempt to compensate for this issue, the expression of validated genes was evaluated in a "Fuji Standard" orchard (city of Caçador, 26 $49^{\circ} 10^{\prime \prime} \mathrm{S}, 50^{\circ} 59^{\prime}$ $25^{\prime \prime} \mathrm{W}$ and $935 \mathrm{~m}$ altitude) where hydrogen cyanamide is not used. The samples consisted of three biological replicates of four plants each. Trees were grafted on M.7 rootstocks in 2002. Forty dormant buds from each tree were harvested at eight different time points from January 2009 to February 2010 (Fig. 1). Harvesting dates and corresponding chilling hours $\left(<7.2{ }^{\circ} \mathrm{C}\right)$ recorded during the 2009/2010 growing cycle are depicted in Table S1. RNAs extracted from all bud samples were also used in RT-qPCR studies. 


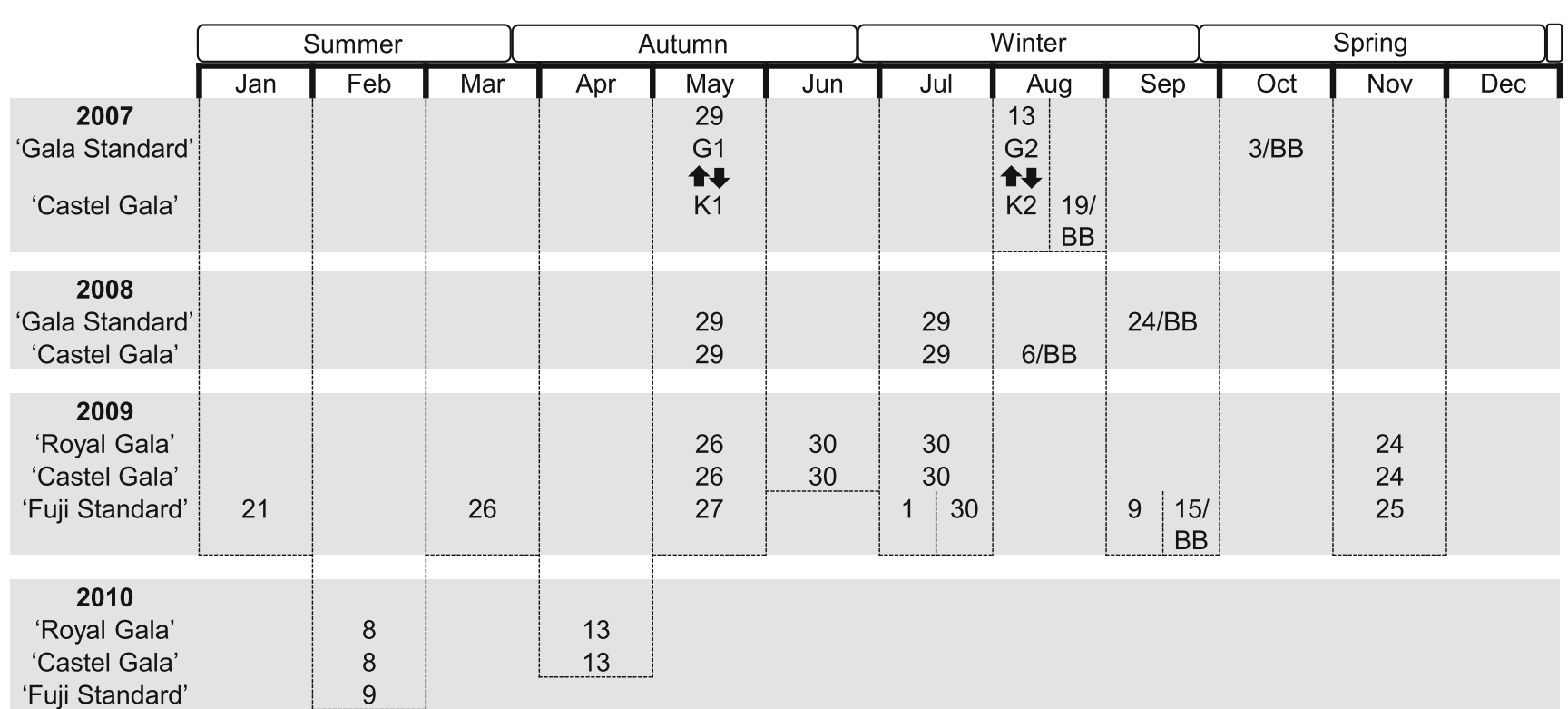

Fig. 1 Sampling strategy for SSH library construction and RT-qPCR analysis. Dates of sampling for each cultivar are depicted. Arrows between samples denote those used in reciprocally subtracted libraries. $B B$ budbreak date (50\% of buds in green tip stage; no sampling occurred);
G1 closed terminal buds of "Gala Standard" harvested in May 2007; G2 closed terminal buds of "Gala Standard" harvested in August 2007; K1 closed terminal buds of "Castel Gala" harvested in May 2007; K2 closed terminal buds of "Castel Gala" harvested in August 2007

\section{RNA Extraction}

Total RNA samples were extracted from 20 frozen buds of each sample (approximately $200 \mathrm{mg}$ ) by $\mathrm{LiCl}$ precipitation using the Zeng and Yang (2002) protocol modified by a purification scale adapted to 2-ml tubes. Each extraction was conducted in three microcentrifuge tubes; the volumes were then pooled before the $\mathrm{LiCl}$ precipitation step. RNA integrity and quantity were monitored by agarose gel electrophoresis and UV quantitation, respectively.

\section{Complementary DNA Library Construction and SSH}

Messenger RNA from the 2007 samples was isolated from $150 \mu \mathrm{g}$ total RNA using the Poly(A) Purist Kit (Ambion) according to the manufacturer's protocol. Subtractions were performed using the PCR-Select cDNA Subtraction Kit (Clontech) according to the manufacturer's instructions, except for the cDNA purification steps. To purify the cDNA, we used the QIAquick PCR Purification Kit (Qiagen) according to the manufacturer's instructions. SSH was performed using tester and driver cDNAs as shown in Fig. 1. Subtracted cDNAs were ligated into the pGEM-T Easy vector (Promega) and transformed into TOP10F' Chemically Competent Escherichia coli cells (Invitrogen). After growing on plates containing SOC medium, white colonies were picked and incubated overnight in 96-deep well plates containing Terrific Broth-ampicillin $(100 \mu \mathrm{g} / \mathrm{ml})$. Glycerol (final concentration of $32.5 \%$ ) was added to each inoculum and the inocula were placed in 96- well U-bottom plates for storage at $-80{ }^{\circ} \mathrm{C}$ until plasmid purification and DNA sequencing.

\section{DNA Sequencing and EST Analysis}

Plasmid DNA was extracted by standard alkaline lysis protocol in deep-well plates and sequenced in the ACTGene Laboratory (Centro de Biotecnologia, UFRGS, Porto Alegre, RS, Brazil) using the automatic sequencer ABI-PRISM 3100 Genetic Analyzer armed with $50 \mathrm{~cm}$ capillaries and POP6 polymer (Applied Biosystems). DNA templates (30-45 ng) were labeled with 3.2 pmol of the primer 5'-GTAAAACGACGGCCAG-3' and $2 \mu \mathrm{l}$ of BigDye Terminator v3.1 Cycle Sequencing RR-100 (Applied Biosystems) in a final volume of $10 \mu \mathrm{l}$. Labeling reactions were performed in a GeneAmp PCR System 9700 (Applied Biosystems) thermocycler with an initial denaturing step of $96{ }^{\circ} \mathrm{C}$ for $3 \mathrm{~min}$, followed by 25 cycles of $96{ }^{\circ} \mathrm{C}$ for $10 \mathrm{~s}, 55{ }^{\circ} \mathrm{C}$ for $5 \mathrm{~s}$ and $60{ }^{\circ} \mathrm{C}$ for $4 \mathrm{~min}$. The labeled samples were purified by isopropanol precipitation followed by $70 \%$ ethanol rinsing. The precipitated products were suspended in $10 \mu \mathrm{l}$ formamide, denatured at $95{ }^{\circ} \mathrm{C}$ for $5 \mathrm{~min}$, icecooled for $5 \mathrm{~min}$ and electro-injected in the automatic sequencer. The sequencing data were collected using the software Data Collection v1.0.1 (Applied Biosystems) programmed with the following parameters: Dye Set "Z"; Mobility File "DT3100POP6\{BDv3\}v1.mob"; BioLIMS Project "3100_Project1"; Run Module 1 
"StdSeq50 POP6 50cm cfv 100"; and Analysis Module 1 "BC-3100SR_Seq_FASTA.saz".

EST visualization and trimming, as well as contig assembly, were performed using the CodonCode Aligner (Licor Inc). Sequences shorter than $100 \mathrm{bp}$ and/or with low PHRED quality $(<20)$ were excluded from the analysis. Sequences were annotated by comparison with the NCBI non-redundant protein public database with the BlastX algorithm (Altschul et al. 1990) using an $E$ value cutoff of $10^{-6}$.

The enrichment of GO terms was determined by two-tailed Fisher's exact tests using an autumn "Royal Gala" spur bud EST library as reference (GenBank identifier LIBEST_015808; Newcomb et al. 2006). Some tests employed the "GO slim" function to identify more general terms. Blast searches, gene ontology annotation from both ESTs and unigenes, and Fisher tests were performed using the Blast2GO software (Conesa et al. 2005).

\section{RT-qPCR Analyses}

The genomic DNA in total RNA samples was removed using the TURBO DNA-free kit (Ambion) according to the manufacturer's protocol. Complementary DNAs were synthesized using the GeneAmp RNA PCR Core kit (Applied Biosystems) according to manufacturer's instructions. Twenty-eight gene-specific primer pairs were designed for each candidate gene (Table S2) using the Primer3 v.0.4.0 software (Rozen and Skaletsky 2000) and Oligo Analyzer (IDT; http://www.idtdna.com). Apple genome accession codes, gene description, subtraction group and the number of ESTs for each unigene are shown in Table 1. RT-qPCR was performed in a StepOnePlus Real-Time PCR System (Applied Biosystems). SYBR Green (Invitrogen) was used to monitor dsDNA synthesis and ROX (Invitrogen) was employed as a passive fluorescence reference. Each biological sample ( $n=2$ for 2007 and 2008 samples; $n=3$ for $2009 / 2010$ samples) was analyzed in technical quadruplicates. The cycling protocol consisted of one step at $95{ }^{\circ} \mathrm{C}$ for $10 \mathrm{~min}$, followed by 40 cycles at $95{ }^{\circ} \mathrm{C}$ for $15 \mathrm{~s}$ and $60{ }^{\circ} \mathrm{C}$ for $1 \mathrm{~min}$, and finished by a dissociation curve between $60{ }^{\circ} \mathrm{C}$ and $95{ }^{\circ} \mathrm{C}$. The specificity of PCR amplifications was assessed by the presence of a single peak in the melting curves and by single amplification products of the expected size in $1.5 \%$ ethidium bromide gel electrophoresis. The mean relative gene expression was calculated by the Pfaffl (2001) method with the $A R C 5, M D H$ and WD40 genes as references (Perini et al. manuscript in preparation). Student's $t$-test and ANOVA followed by Tukey's test were used to evaluate the statistical significance of differences in mean expression levels between samples when appropriate.

\section{Results}

\section{SSH Library Construction}

To explore the physiological contrast of dormancy progression between "Gala Standard" (G) and "Castel Gala" (K), closed terminal buds of both cultivars harvested on May 29 (1) and August 13, 2007 (2) from commercial orchards were used to construct four SSH libraries. The sampling strategy was based on historical phenological germplasm records for these cultivars. According to Denardi and Seccon (2005), both cultivars enter dormancy in May, but budbreak in "Castel Gala" usually occurs in the middle of August, while for "Gala Standard" it occurs in late September or early October. Hence, SSH libraries were designed to represent genes enriched during early dormancy (named G1-K1 and K1$\mathrm{G} 1)$, dormancy maintenance (G2-K2) and dormancy release (K2-G2). The tester and driver cDNAs were designated as shown in Fig. 1.

The SSH technique yielded 4,241 clones of putatively differentially expressed genes with transcript-derived fragment sizes ranging from $\sim 100$ to $700 \mathrm{bp}$. From each library, 384 clones (1,536 in total) were sequenced, and the highquality sequences obtained (1,331) were assembled into 1 , 019 unigenes. All ESTs and unigenes were functionally annotated by BlastX against the NCBI non-redundant database and by Gene Ontology (GO) terms (Conesa et al. 2005). Annotated ESTs were submitted to GenBank under accession numbers JZ480898 to JZ482228. The best BlastX hits and significant GO terms of assembled sequences and singlets are presented in Table S3. The most frequent GO terms belonging to the "biological process" domain are depicted in Fig. 2. Several of these terms were represented in all four libraries, such as "response to abiotic stimulus", "response to stress", "transport", "carbohydrate metabolic process", "protein modification process" and "nucleobase, nucleotide and nucleic acid metabolic process". We identified unique GO terms in each library, such as "response to endogenous stimulus" and "reproduction" for K1-G1, "signal transduction" for G1-K1, "photosynthesis" for K2-G2, and "biosynthetic process" for G2-K2 (Fig. 2).

To identify significantly enriched GO terms for each library, we performed Fisher's exact tests (Conesa et al. 2005) on the full sets of functionally annotated ESTs using an autumn "Royal Gala" spur bud EST library as reference (Newcomb et al. 2006). The tests revealed the significantly enriched GO terms for each library (Table 2). In the G1-K1 subtraction, only two GO terms were significantly overrepresented, namely, "small molecule metabolic process" and "cellular amino acid and derivative metabolic process". In the K1-G1 subtraction, no GO terms were overrepresented. In the samples from August 2007 (G2-K2 and $\mathrm{K} 2-\mathrm{G} 2$ ), the results revealed a clear overall functional 
Table 1 Candidate genes selected from differentially expressed transcripts of apple cultivars "Gala Standard" versus "Castel Gala" identified by SSH

\begin{tabular}{|c|c|c|c|c|}
\hline Name & Subtraction group & EST count & Unigene best description (Blast2GO) & Genome acession code \\
\hline ABD1 & G1-K1 & 1 & ap2 domain class transcription factor & MDP0000308922 \\
\hline $\mathrm{ABD} 2$ & G1-K1 & 1 & Histone $\mathrm{h} 2 \mathrm{a}$ & MDP0000831145 \\
\hline ABD3 & G1-K1 & 2 & Low-temperature inducible & MDP0000124634 \\
\hline ABD4 & $\mathrm{G} 1-\mathrm{K} 1 / \mathrm{G} 2-\mathrm{K} 2$ & $1 / 2$ & Low-temperature-induced 65 -kda protein & MDP0000937986 \\
\hline ABD5 & $\mathrm{G} 1-\mathrm{K} 1 / \mathrm{K} 2-\mathrm{G} 2$ & $1 / 1$ & Histone $\mathrm{h} 2 \mathrm{a}$ & MDP0000309757 \\
\hline ABD6 & $\mathrm{G} 2-\mathrm{K} 2$ & 2 & Actin-related protein 6 & MDP0000255932 \\
\hline ABD7 & $\mathrm{G} 2-\mathrm{K} 2$ & 1 & Alcohol dehydrogenase class III & MDP0000156866 \\
\hline ABD8 & $\mathrm{G} 2-\mathrm{K} 2$ & 2 & ap2 domain-containing transcription factor & MDP0000137561 \\
\hline ABD9 & $\mathrm{G} 2-\mathrm{K} 2$ & 4 & Calmodulin-binding transcription activator 1 & MDP0000255517 \\
\hline ABD10 & $\mathrm{G} 2-\mathrm{K} 2$ & 3 & Constans-like protein & MDP0000202669 \\
\hline ABD11 (MdDHN2) & $\mathrm{G} 2-\mathrm{K} 2$ & 26 & Dehydrin-like protein & MDP0000698024 \\
\hline ABD12 (MdDHN4) & $\mathrm{G} 2-\mathrm{K} 2$ & 11 & Dehydrin-like protein & MDP0000360414 \\
\hline ABD13 (MdDHN6) & $\mathrm{G} 2-\mathrm{K} 2$ & 5 & Dehydrin & MDP0000265874 \\
\hline ABD14 & $\mathrm{G} 2-\mathrm{K} 2$ & 1 & Dormancy-associated MADS-box transcription factor & MDP0000322567 \\
\hline ABD15 & $\mathrm{G} 2-\mathrm{K} 2$ & 4 & Galactinol synthase & MDP0000209143 \\
\hline ABD16 & $\mathrm{G} 2-\mathrm{K} 2$ & 7 & Gibberellin-regulated protein & MDP0000937996 \\
\hline ABD17 & $\mathrm{G} 2-\mathrm{K} 2$ & 1 & Gras family transcription factor & MDP0000159531 \\
\hline ABD18 & $\mathrm{G} 2-\mathrm{K} 2$ & 3 & Gras family transcription factor & MDP0000264347 \\
\hline ABD19 & $\mathrm{G} 2-\mathrm{K} 2$ & 1 & Inducer of cbf expression 1 & MDP0000304669 \\
\hline ABD20 & $\mathrm{G} 2-\mathrm{K} 2$ & 1 & Lustrin a-like & MDP0000240332 \\
\hline ABD21 & $\mathrm{G} 2-\mathrm{K} 2$ & 1 & Nac domain ipr003441 & MDP0000169485 \\
\hline ABD22 & $\mathrm{G} 2-\mathrm{K} 2$ & 1 & Trehalose 6-phosphate synthase & MDP0000258781 \\
\hline ABD23 & K1-G1 & 1 & Della protein & MDP0000662303 \\
\hline ABD24 & K1-G1 & 3 & Elongation factor ef-2 & MDP0000293608 \\
\hline $\mathrm{ABD} 25$ & K1-G1 & 2 & Rare cold inducible protein & MDP0000361927 \\
\hline ABD26 & K1-G1 & 2 & Rare cold inducible protein & MDP0000201755 \\
\hline ABD27 & K1-G1 & 1 & Sterol c-14 reductase & MDP0000285817 \\
\hline ABD28 & K2-G2 & 1 & Histone $\mathrm{h} 2 \mathrm{a}$ & MDP0000205983 \\
\hline ARC5 & Reference gene & - & Accumulation and replication of chloroplast 5 & MDP0000138874 \\
\hline $\mathrm{MDH}$ & Reference gene & - & Malate dehydrogenase & MDP0000197620 \\
\hline WD40 & Reference gene & - & transcription factor WD40-like repeat domain & MDP0000168479 \\
\hline
\end{tabular}

Subtraction group, number of ESTs corresponding to each unigene and best Blast2GO unigene description are shown. Genome accessions are provided based on codes presented by the "Malus $\times$ domestica Genome" database (http://genomics.research.iasma.it/). ABD apple bud dormancy

distinction between the sets. G2-K2 subtraction was significantly enriched in GO terms related to response to abiotic stress and carbohydrate metabolism, while K2-G2 subtraction was enriched with terms related to cell parts and photosynthesis (Table 2).

\section{Validation of Dormancy-Related Candidate Genes} by RT-qPCR

From the 1,019 unigenes identified by SSH, we selected 28 candidates based on bioinformatics analysis and putative participation in dormancy regulation (Table 1; Taji et al. 2002; He et al. 2003; Penna 2003; Horvath 2009; Kumar and Wigge 2010; Yant et al. 2010; Kurbidaeva and Novokreshchenova
2011; van der Schoot and Rinne 2011; Bailey-Serres et al. 2012). Because the SSH procedure may yield false positives (Kuhn 2001), we reassessed candidate gene expression by RTqPCR in the original RNA samples (harvested in 2007) and a second group of RNAs extracted from closed terminal buds harvested in 2008 from the same "Gala Standard" and "Castel Gala" apple trees at approximately the same dates (see Materials and Methods). SSH results were considered validated when the differential gene expression profiles between cultivars were confirmed in both RNA groups by RT-qPCR with statistical significance ( $p<0.05$; Fig. 3; Fig. S1).

Differential expression was validated by RT-qPCR for 17 of the 28 candidate genes selected from SSH. These 17 genes code for alcohol dehydrogenase (ADH; ABD7), GA-stimulated 
Fig. 2 Gene Ontology $(G O)$ terms belonging to the biological process domain attributed to unigene groups identified in $\mathrm{SSH}$ libraries. Dormant buds of "Gala Standard" $(G)$ or "Castel Gala" $(K)$ harvested in May $(1)$ or August 2007 (2) were used to construct four SSH libraries representing genes in early dormancy (G1-K1 and K1-G1), dormancy maintenance (G2-K2) and dormancy release (K2-G2). Only GO term classifications populated by at least ten unigenes are shown. The number of unigenes annotated within each term is shown

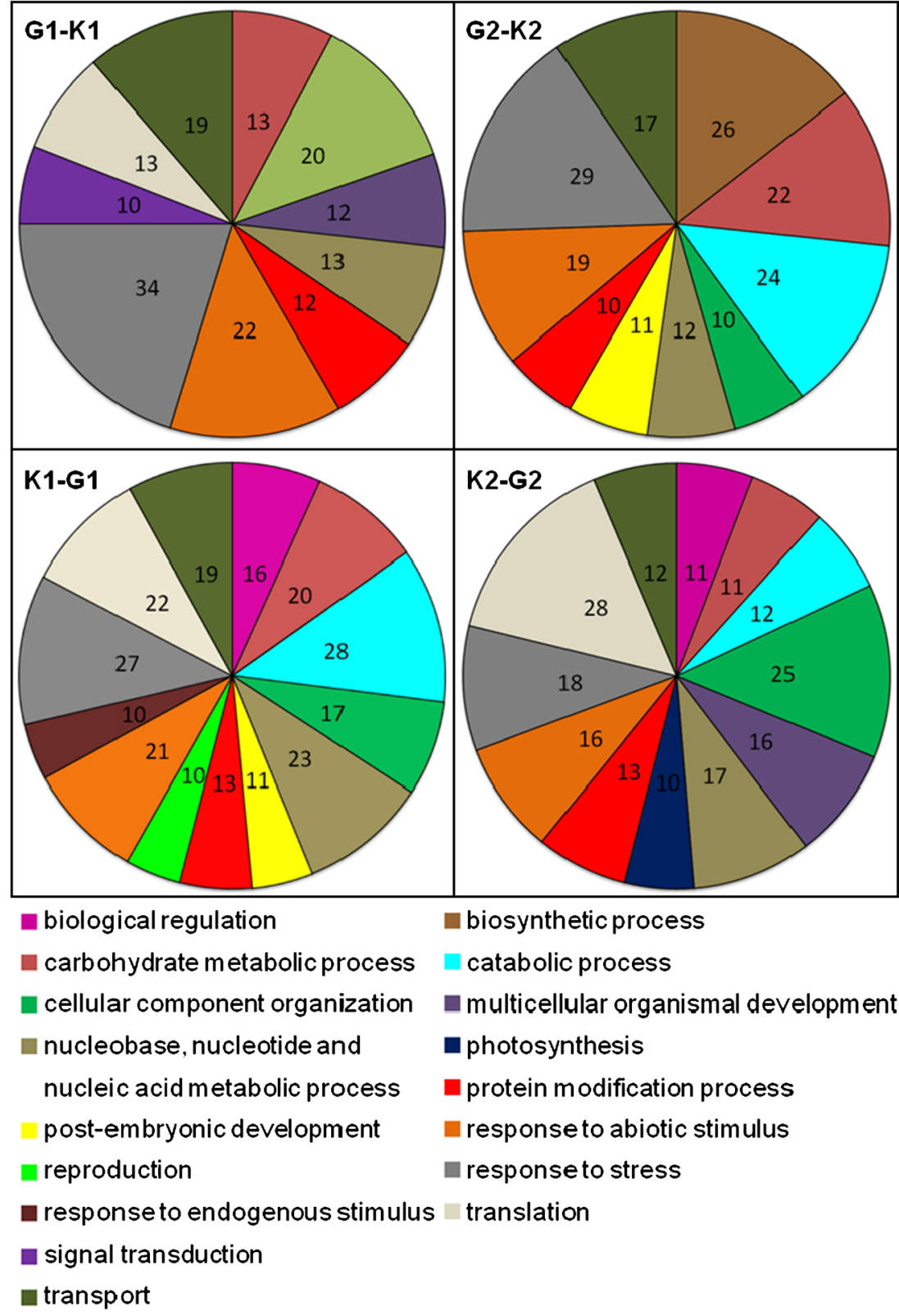

transcript 1 (GAST1; ABD16), galactinol synthase (GolS; ABD15), three dehydrins (DHNs; ABD11, ABD12 and ABD13), histone H2A 12 (HTA12; ABD28), histone H2A variant H2A.Z 8 (HTA8; ABD5), low-temperature inducible 65 (LTI65; ABD4) and the transcription factors APETALA2 (AP2; ABD8), calmodulin-binding transcription activator 1 (CAMTA1; ABD9), DAM (ABD14), GA insensitive/ repressor of GA1/scarecrow (GRAS; ABD17), inducer of CBF expression 1 (ICE1; ABD19), no apical meristem/ ATAF2/cup-shaped cotyledon 2 (NAC; ABD21), related to AP2.12 (RAP2.12; ABD1) and scarecrow-like (SCL; ABD18; Fig. 3). Interestingly, two of these genes were found and validated in distinct subtractions. The expression of $A B D 4$ was higher in $\mathrm{G} 1-\mathrm{K} 1$ and $\mathrm{G} 2-\mathrm{K} 2$, and the gene encoding $A B D 5$ was expressed at higher levels in the G1-K1 and K2-G2 libraries (Fig. 3).

Eleven SSH-selected candidate genes were not validated by RT-qPCR, including those putatively encoding actinrelated protein 6 (ARP6; ABD6), CO-like (ABD10), DELLA (ABD23), ESKIMO1 (ABD20), FACKEL (ABD27), histone H2A variant H2A.Z 11 (HTA11; ABD2), low expression of osmotically responsive genes 1 (LOS1; ABD24), LTI (ABD3), two rare cold-inducible genes (RCI1 and RCI2; ABD25 and ABD26) and trehalose-6-phosphate synthase (T6PS; ABD22; Fig. S1). Out of the ten candidate genes chosen from the May 2007 samples (G1-K1 and K1- 
Table 2 Significantly enriched $(p<0.05)$ GO classifications after projection to more generic $\mathrm{GO}$ terms related to plants (GO plant slim, Conesa et al. 2005)

\begin{tabular}{llll}
\hline Library & GO term description & $p$ value & EST number \\
\hline G1-K1 & $\begin{array}{l}\text { Small molecule metabolic } \\
\text { process }\end{array}$ & $1.23 \times 10^{-4}$ & 22 \\
& $\begin{array}{l}\text { Cellular amino acid and } \\
\text { derivative metabolic process }\end{array}$ & $1.23 \times 10^{-4}$ & 22 \\
K1-G1 & Not significant & - & - \\
G2-K2 & Carbohydrate metabolic process & $3.33 \times 10^{-6}$ & 37 \\
& Response to stress & $6.79 \times 10^{-5}$ & 68 \\
& Response to abiotic stimulus & $2.71 \times 10^{-4}$ & 55 \\
& Response to stimulus & $1.88 \times 10^{-3}$ & 81 \\
K2-G2 & Cell part & $5.73 \times 10^{-5}$ & 192 \\
& Cellular component organization & $1.14 \times 10^{-3}$ & 43 \\
& Membrane & $2.07 \times 10^{-3}$ & 88 \\
& Cellular process & $2.57 \times 10^{-3}$ & 162 \\
& Intracellular organelle & $2.73 \times 10^{-3}$ & 136 \\
& Organelle & $2.73 \times 10^{-3}$ & 136 \\
& Photosynthesis & $2.87 \times 10^{-3}$ & 15 \\
& Intracellular part & $3.02 \times 10^{-3}$ & 163 \\
& Lipid metabolic process & $4.49 \times 10^{-3}$ & 15 \\
\hline
\end{tabular}

G1), seven were not validated by RT-qPCR (70 \%). However, only four of the 20 genes tested in the August 2007 samples (G2-K2 and K2-G2) were not confirmed (20\%).

\section{Characterization of Dormancy-Related Genes by RT-qPCR in Different Apple Cultivars}

All 17 validated genes had their transcript accumulation profiles further analyzed by RT-qPCR in samples of closed terminal buds from three different apple tree cultivars collected in 2009/2010. RNA samples were extracted from closed terminal buds harvested in 2009 and 2010 from "Royal Gala" and "Castel Gala" trees in a nearby commercial orchard. The 450 chilling hours accumulated by "Royal Gala" and "Castel Gala" samples in July 2009 (Table S1) is sufficient to break the dormancy of "Castel Gala" buds but not "Royal Gala" buds, as determined under controlled conditions (Anzanello 2012). Accordingly, "Castel Gala" buds were visibly more advanced towards dormancy completion in July 2009, as shown by the presence of a higher number of brindles with silver tips (which were not sampled).

Because the experimental area sampled in 2009 belonged to a commercial orchard, dormancy release was artificially forced with the application of hydrogen cyanamide after our sampling. This is the reason for the lack of sampling points between July and November 2009. To compensate for this gap between sampling points, closed terminal buds of "Fuji Standard" trees from a third experimental area were transcriptionally profiled. "Fuji Standard" is a high CR cultivar (Botelho et al. 2006) and the transcriptional profiles of the selected genes in these samples were explored to help confirm the patterns associated with CR fulfillment and for genotype-dependent comparisons (see the following section). No hydrogen cyanamide was sprayed in the "Fuji Standard" orchard.

The quantitative expression analysis of the 17 genes previously validated by RT-qPCR on samples harvested in 2009/ 2010 revealed that ten genes exhibited the same pattern of transcript accumulation revealed by SSH in "Royal Gala" and "Castel Gala" samples - ABD1, ABD4, ABD5, ABD11, $A B D 12, A B D 13, A B D 14, A B D 16, A B D 21$ and $A B D 28$ (Fig. 4). $A B D 11$ and $A B D 16$ - showed the most contrast in levels of steady-state mRNA between "Royal Gala" and "Castel Gala" in samples harvested in July 2009 (winter), with much higher levels in "Royal Gala" than in "Castel Gala", but dropping to similar levels at the beginning of summer (November/December 2009; Fig. 4). In accordance with this observation, the ESTs for these two genes were among the most redundantly sequenced in the G2-K2 subtraction pool (26 and seven times, respectively; Table 1). Although not as prominent, $A B D 12, A B D 13, A B D 14$ and $A B D 21$ also exhibited higher transcript accumulations in "Royal Gala" than in "Castel Gala" in July 2009, with lower and similar levels in the spring and summer samples. Contrarily, $A B D 1, A B D 5$ and $A B D 28$ exhibited higher transcript levels in "Castel Gala" than in "Royal Gala" samples harvested in July 2009. In the spring, however, inverted levels were observed between the cultivars (November 2009; Fig. 4). In contrast to all the others, $A B D 4$ exhibited differences in transcript levels only in samples harvested at the end of autumn 2009 (May), being higher in "Royal Gala" than in "Castel Gala". Similar levels of transcripts for this gene were observed for both cultivars from June 2009 to April 2010, although it is worth mentioning the remarkable induction of expression ( $\sim 80$-fold) in the winter compared to the summer (Fig. 4).

The transcript profiles of the other seven validated genes, namely $A B D 7, A B D 8, A B D 9, A B D 15, A B D 17, A B D 18$ and $A B D 19$, were different from those observed in the SSH and RT-qPCR results. For these genes, the expected profile is for "Royal Gala" to display more transcript accumulation during the winter (July 2009) because all these genes were identified in the G2-K2 subtraction. However, $A B D 7, A B D 8$, $A B D 9, A B D 17$ and $A B D 19$ displayed a peak of transcript accumulation in "Castel Gala" rather than "Royal Gala" in the July 2009 samples (Fig. S2). In addition, these genes, as well as $A B D 18$, did not display a clear seasonal pattern of transcript accumulation, as did most of the validated genes in the same subtraction. $A B D 15$ had similar levels of transcript accumulation for both cultivars over the 2009/2010 sampling points, with a noteworthy peak of expression $(\sim 70-$ fold) during the winter (Fig. S2). 


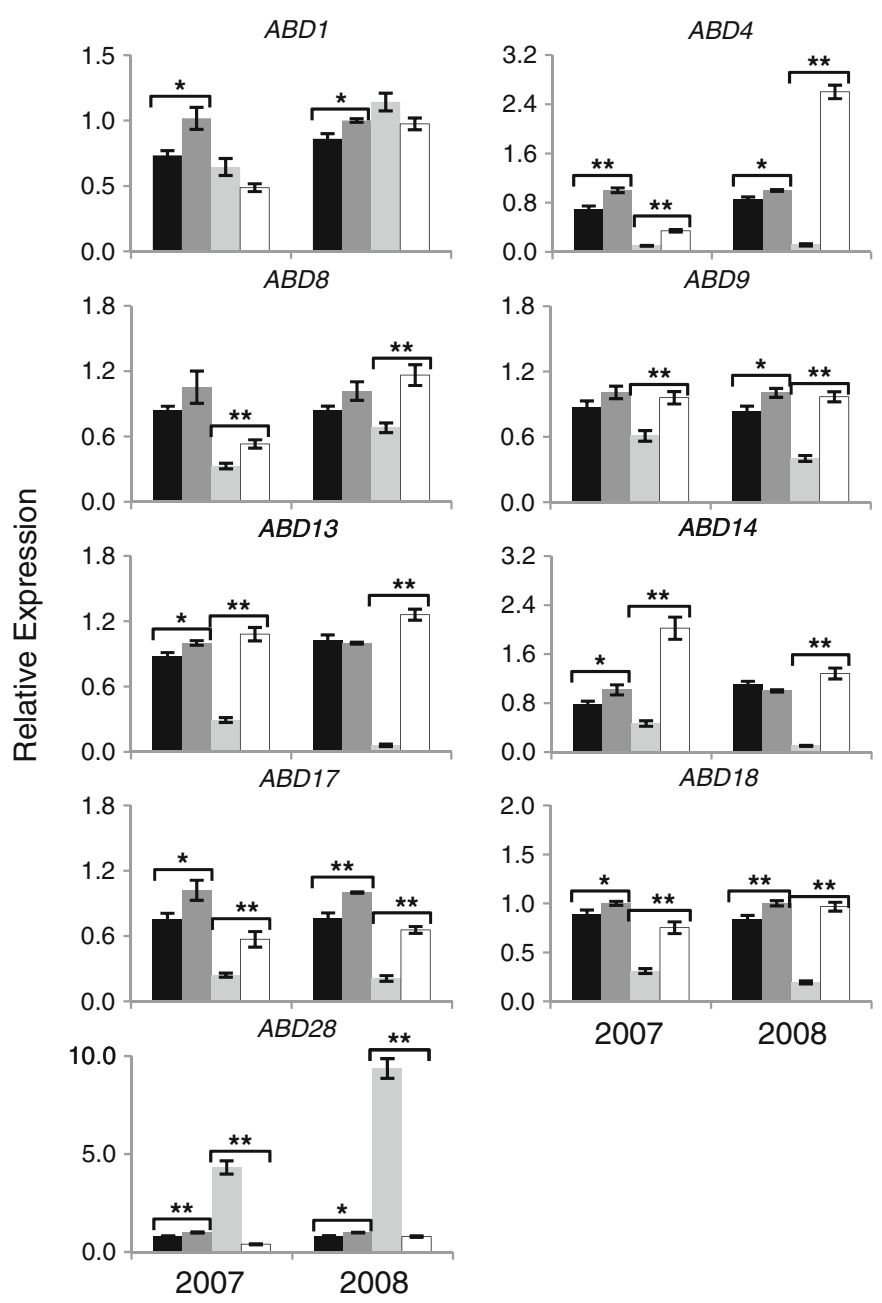

Fig. 3 RT-qPCR relative expression levels of 17 candidate genes identified by SSH, validating this screening technique. Subtractive cDNA libraries were constructed as described in the legend for Fig. 2. The subtraction groups in which each transcript was identified are displayed in Table 1. RT-qPCRs were performed with the 2007 original samples (used for SSH library construction) and also with two additional 2008

Interestingly, only samples harvested in May 2009 (autumn), July 2009 and February 2010 (summer) showed statistically significant differential expression between the cultivars for all 17 genes (Fig. 4; Fig. S2). However, samples harvested in June 2009 (winter), November 2009 (spring) and April 2010 (autumn) did not show significant differences in transcript accumulation.

The same 17 genes were assayed by RT-qPCR in closed terminal bud samples harvested from "Fuji Standard" apple trees. $A B D 4, A B D 5, A B D 11, A B D 13, A B D 14, A B D 16$, $A B D 21$ and $A B D 28$ had almost overlapping seasonal patterns of transcript accumulation in the 2009/2010 "Royal Gala" and "Fuji Standard" samples (Figs. 4 and 5). Transcript accumulation for these genes decreased close to the end of dormancy (September 15th), except for the histones (ABD5 and ABD28; Fig. 5), in agreement with "Castel Gala" (Fig. 4). However,
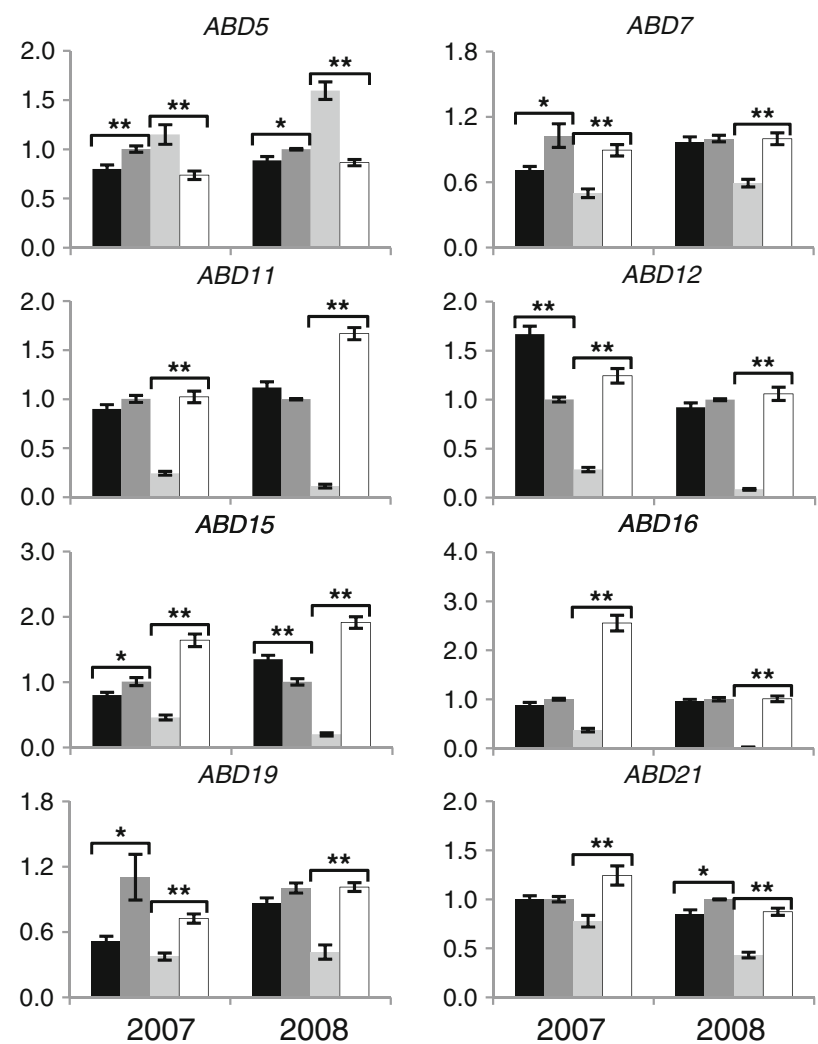

samples from both cultivars. Black, "Castel Gala" first sampling (K1); dark grey, "Royal Gala" first sampling (G1); light grey, "Castel Gala" second sampling (K2); white, "Royal Gala" second sampling (G2). Relative transcript levels in the G1 sampling were set to 1. Standard error bars are shown. Asterisks indicate statistical significance between cultivars at the same sampling point (unpaired $t$ test: $* * p<0.01,{ }^{*} p<0.05$ )

$A B D 8, A B D 9, A B D 17$ and $A B D 19$ were expressed in a very similar fashion between "Fuji Standard" and "Castel Gala" (Figs. S2 and S3). ABD4 and $A B D 15$ exhibited the same seasonal patterns in the three cultivars, with a noticeable peak of transcript accumulation during the winter (Figs. S2 and S3).

\section{Genotype-Dependent Expression of Validated Genes}

To better assess genotype-related differences in the expression of validated genes, the RT-qPCR data derived from the three apple cultivars sampled on July 30, 2009 were relativized to "Castel Gala" mRNA levels (Fig. 6). These samples were harvested nearly at the same time (9 to 10:00 am) and experienced similar amounts of chilling hours (Table S1). ABD14 was more highly expressed in the high $\mathrm{CR}$ cultivars, while $A B D 28$ was more highly expressed in "Castel Gala". $A B D 4$, 


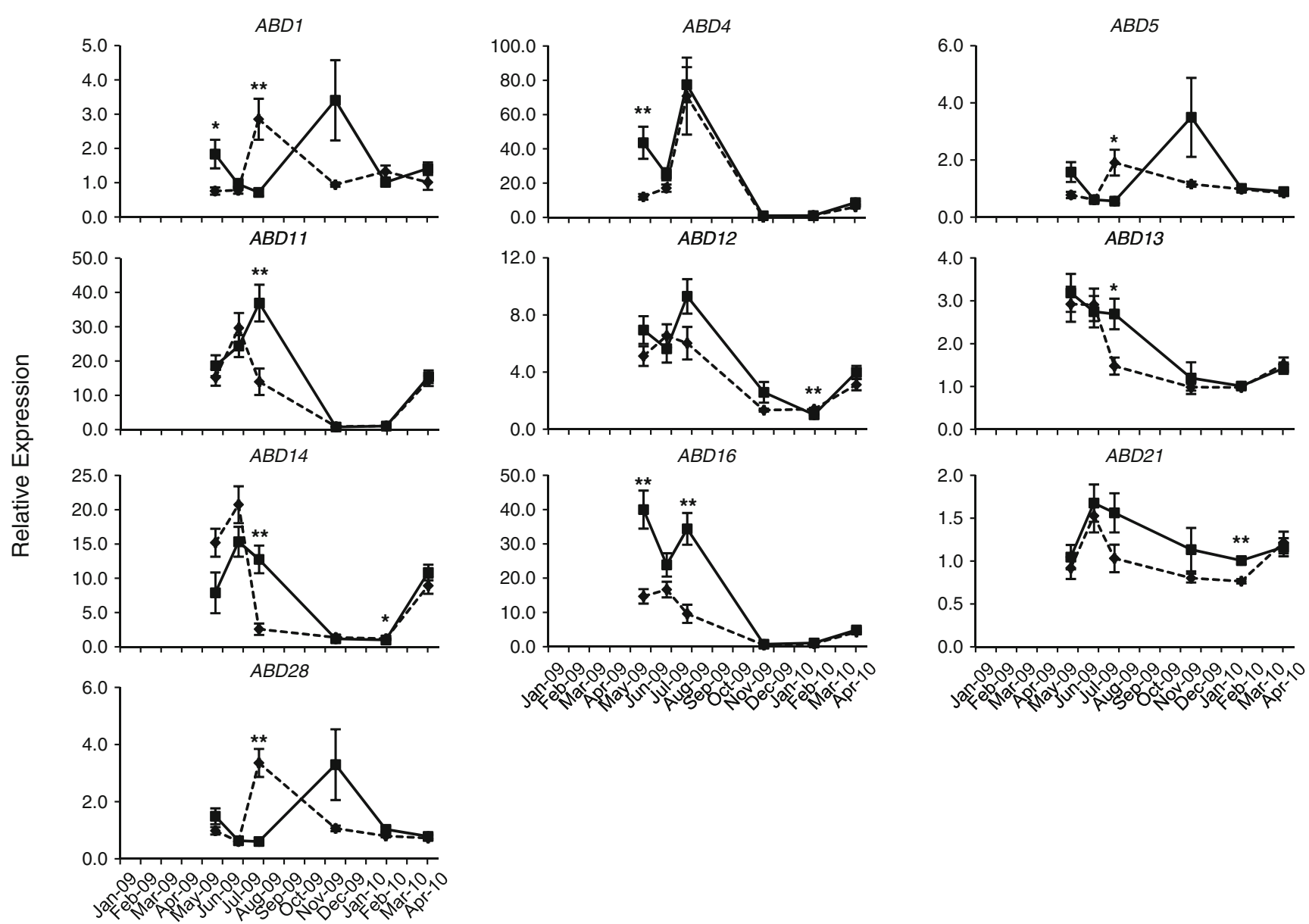

Fig. 4 RT-qPCR relative expression levels of ten genes over 2009/2010. RT-qPCRs were performed using RNAs extracted from closed terminal bud samples harvested from "Royal Gala" and "Castel Gala" apple trees. Solid lines, "Royal Gala"; dashed lines, "Castel Gala". Relative transcript levels in the February 2010 sample of "Royal Gala" were set to 1.

$A B D 8, A B D 11, A B D 12, A B D 15, A B D 16, A B D 18, A B D 19$ and $A B D 21$ showed higher expression only in the "Fuji Standard" samples. No significant difference was observed in $A B D 7$ gene expression. Unexpectedly, $A B D 1$ and $A B D 17$ exhibited similar transcript levels in bud samples from "Castel Gala" and "Fuji Standard" and lower levels in "Royal Gala". Finally, $A B D 9$ expression differed statistically only between the "Fuji Standard" and "Royal Gala" samples, while $A B D 5$ and $A B D 13$ differed only between the "Castel Gala" and "Royal Gala" samples.

\section{Discussion}

Apple Bud Dormancy and the "Gala Standard" versus the "Castel Gala" Model

Naturally occurring genetic variation provides a good starting point for characterizing biological phenomena, and differential
Standard error bars are shown. Asterisks indicate statistical significance between cultivars to the same sampling point (unpaired $t$ test: $* * p<0.01$, $* p<0.05)$. $A B D 12$ and $A B D 21$ had $t$ test $p$ values of 0.066 and 0.076 , respectively, in July 2009

expression screening may point to molecular mechanisms associated with such variance. In addition to the research opportunity, crop genetic variation is the basis for the establishment of new varieties (Arora et al. 2003; Fernie et al. 2006). In the Castel Gala apple cultivar, a low CR cultivar derived from a "Gala Standard" background, budburst is nearly a month earlier compared to "Gala Standard" (or "Royal Gala") under natural field conditions (Denardi and Seccon 2005; Anzanello 2012). With the availability of this unique germplasm resource for comparing the CR for bud dormancy release in apple trees, our strategy was to identify genes putatively involved in bud dormancy control. To identify the effects of the "Castel Gala" mutation over its original genetic counterpart at the transcriptional level, two reciprocal subtractions between cultivars were made when both cultivars had fully established bud sets (May 29, 2007 samples). These samples provided an opportunity to study differences in dormancy regulation between quite similar genetic backgrounds, while avoiding transcriptional information with no direct relationship with the mutation. Reciprocal subtractions derived from samples harvested on August 13 


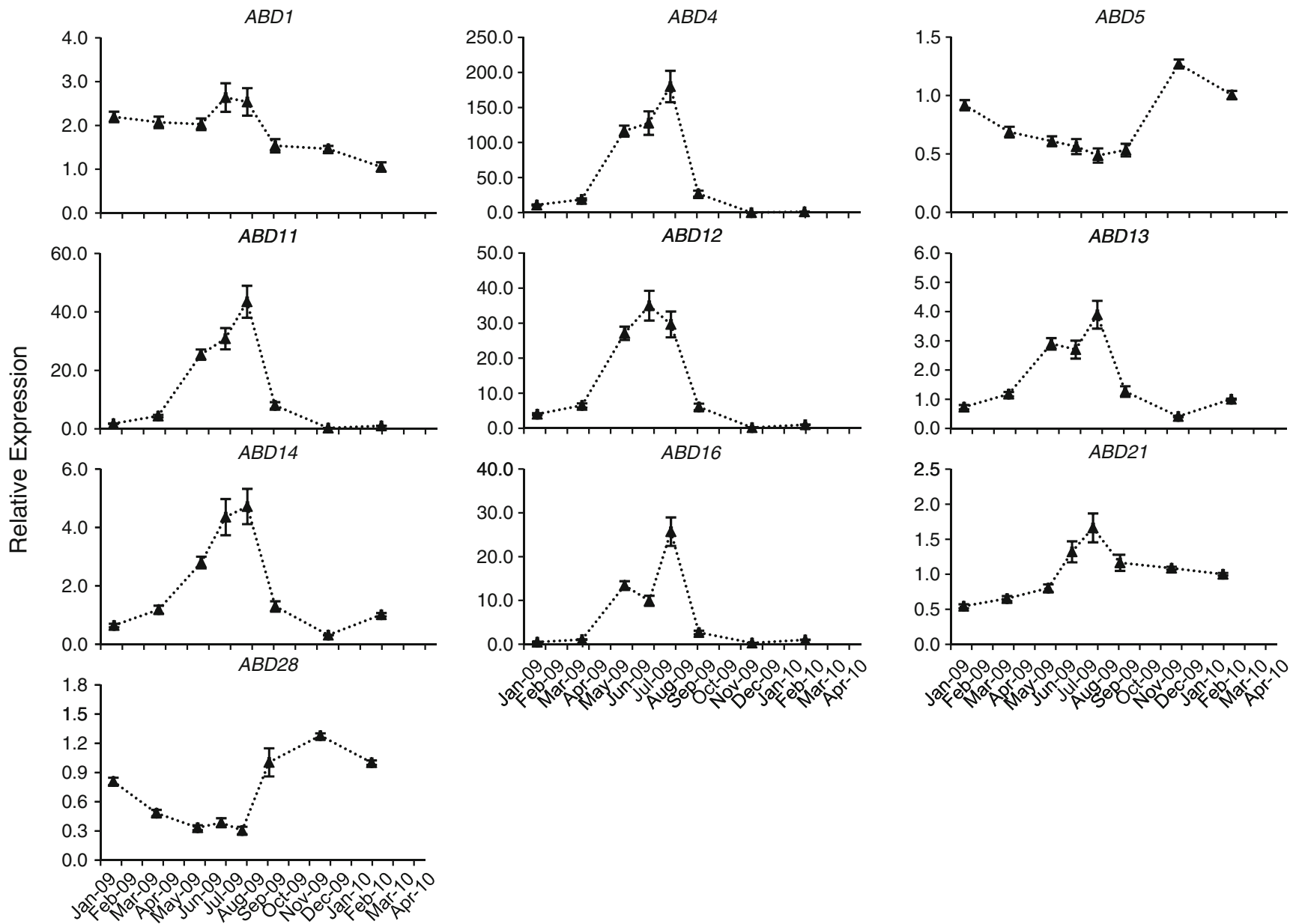

Fig. 5 RT-qPCR relative expression levels of ten genes over 2009/2010. RT-qPCRs were performed using RNA samples extracted from closed terminal bud samples harvested from "Fuji Standard" apple trees. Dotted

2007 were undertaken to identify differential expression at a time point when closed terminal buds were mostly different between cultivars. These differences were inferred by the proximity of the budbreak date of "Castel Gala" and historical phenological data (Fig. 1; Denardi and Seccon 2005; Anzanello 2012).

Functional Enrichment of Genes Identified by SSH

Despite the distinct dormancy stages displayed by the buds used in the construction of the four SSH libraries, the sequencing and characterization of derived ESTs revealed common functional roles. Interestingly, closed terminal buds from K2G2, which had begun the dormancy release process, exhibited a pool of unigenes characterized by the same GO terms as those derived from the fully dormant subtraction G2-K2 (Fig. 2). Except for a few exclusive GO terms attributed to some groups of unigenes from each cultivar, overall they shared the same GO terms. Other studies of bud dormancy using the SSH technique have described subtractions with transcripts belonging to overlapping functions, even between lines, "Fuji Standard". Relative transcript levels in the February 2010 sample of "Fuji Standard" were set to 1. Standard error bars are shown

reciprocal libraries (Leida et al. 2010; Krishnaraj et al. 2011). This functional equivalence indicates that basal metabolic pathways are equally active throughout the dormancy cycle, although the genes involved may not be necessarily the same.

Fisher's exact test (Conesa et al. 2005) was used to identify GO terms over-represented in our EST sets in comparison to an external dormant bud EST library (Newcomb et al. 2006). The four subtractions showed functional profiles consistent with the expected physiological stage of the buds (Table 2). The G1-K1 subtraction was enriched in metabolism-related GO terms. This result is analogous to that found in poplar, where massive metabolic changes take place during dormancy entrance, at the same time that bud tissues cold-acclimate (Ruttink et al. 2007). The EST pool resulting from the G2K2 subtraction also presented GO term enrichment towards metabolism. In addition, GO terms related to stress response and abiotic stimuli were over-represented in G2-K2. This result is in close agreement with Leida et al. (2010), who found enrichment of stress-related genes in a very similar subtraction-derived library in peach. The K2-G2 subtraction showed a significant enrichment of GO terms related to 
Fig. 6 Expression of validated genes among the three apple genotypes sampled on July 30th 2009. RT-qPCR data were adjusted using "Castel Gala" mRNA levels (black column) for calibration. Dashed columns, "Royal Gala"; dotted columns "Fuji Standard". Standard error bars are shown. Means with the same letter are not significantly different for $p<0.05$ by ANOVA followed by Tukey's test

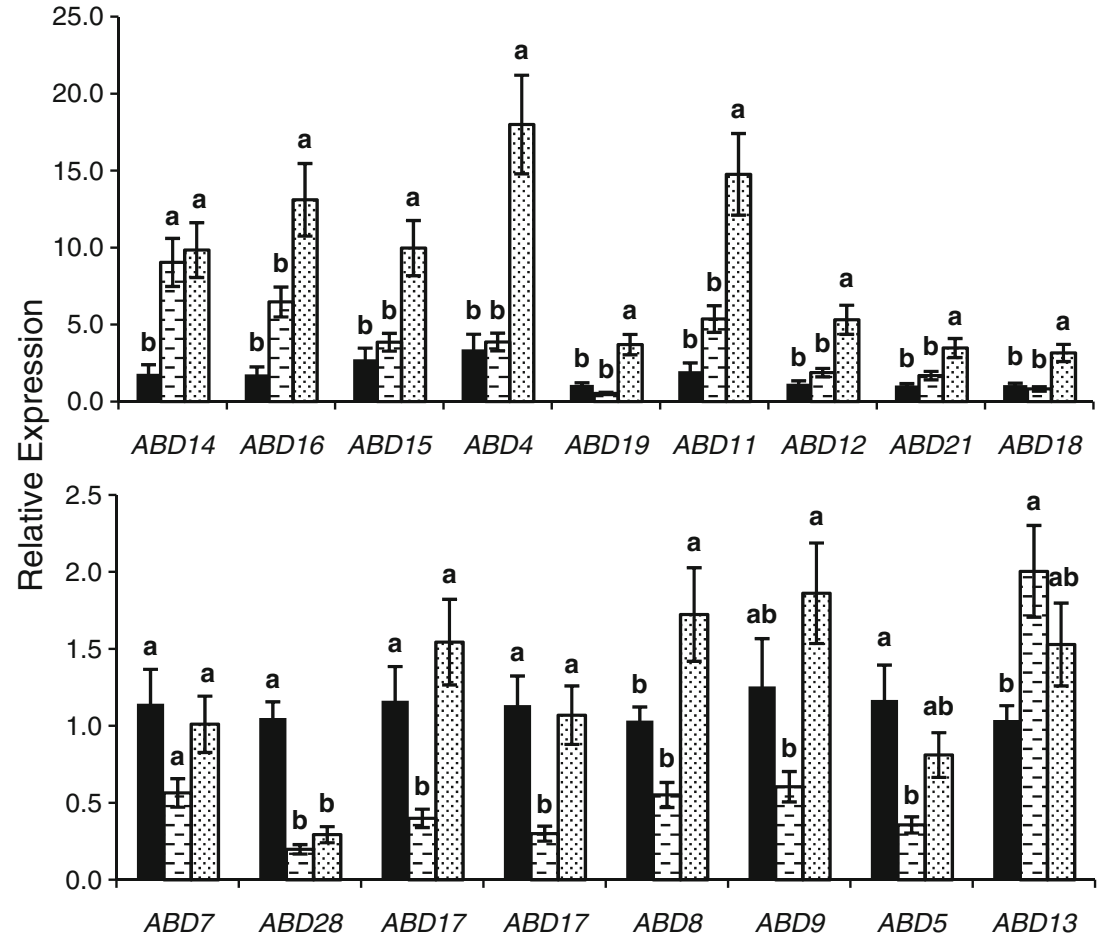

growth and photosynthesis. Likewise, Pacey-Miller et al. (2003) reported higher transcription levels of genes related to cell structure, plant growth, photosynthesis and metabolism during dormancy release in grapevine. Furthermore, "Castel Gala" buds flushed 6 days after the August 2007 sampling date; hence, the transcriptional program at this harvesting point could reflect preparation for growth resumption (Table 2).

Validation of Apple Dormancy-Related Candidate Genes by RT-qPCR

To validate the differential expression of selected candidate genes by RT-qPCR, we used closed terminal buds harvested in 2007 and 2008 from the same trees sampled for the SSH. From 28 specifically selected genes, 17 (60.7\%) displayed the expression patterns previously identified. This number of validated genes is high compared to other dormancy studies. In a recent approach using SSH to address a list of dormancyrelated genes in peach, Leida et al. (2010) found that only a low percentage (approximately 15 to $48 \%$ ) of the clones were validated. Similar results were also reported for bud dormancy in Japanese apricot (Yamane et al. 2008). The number of genes confirmed as differentially expressed was significantly higher in G2-K2 and K2-G2 subtractions than in G1-K1 and K1-G1 subtractions. This result is in agreement with the higher contrast of functional classes (GO terms) detected previously by Fisher's test in G2-K2 and K2-G2 subtractions (Table 2), whose samples were in contrasting dormancy stages, as reflected by the distinct budbreak dates of both cultivars (Fig. 1).

Transcriptional Characterization of Apple Bud Dormancy-Related Candidate Genes

With the aim of better characterizing the expression of validated genes, we profiled RNAs derived from closed terminal buds harvested throughout the 2009/2010 cycle from three contrasting CR apple tree cultivars. The comparison of transcript accumulation in "Royal Gala" and "Castel Gala" bud samples growing under the same field conditions was a good opportunity to further study the differential expression found through the SSH technique. "Castel Gala" and "Royal Gala" scions were grafted onto M.9 and Marubakaido rootstocks, respectively, with the latter bearing an M.9 interstock. The flowering periods of "Gala" trees do not differ between these two rootstock systems (Petri et al. 2012). Additionally, July 2009 (winter) RT-qPCR data allowed the comparison of samples at a time point when the phenological differences between cultivars were evident because "Castel Gala" trees were in a more advanced stage of dormancy, close to budburst. The complementary "Fuji Standard" sampling was useful to confirm seasonal gene expression profiles, to evaluate the association of expression patterns with a low (Castel Gala) or high (Royal Gala) CR cultivar and to assess transcription profiles in a non-"Gala" genetic background ("Fuji Standard").

The transcript accumulation analysis of the 17 candidate genes would allow the identification of genes that could be 
assigned to roles in dormancy regulation. Possible roles for genes putatively associated with dormancy can be investigated by studying their seasonal expression and then linking the data to bud physiology (Mathiason et al. 2009; Yamane et al. 2011). It would be expected for a dormancy-related gene to be regulated during late autumn and winter, and this was observed for most of the validated genes presented here. Although the genes profiled here represent a wide range of cellular functions, such as cold-responsiveness, gibberellin signaling, hypoxia signaling and chromatin remodeling, we identified several transcripts sharing the same patterns of transcript accumulation. These results suggest that many pathways regulate dormancy progression in apple, as reported previously for dormancy induction in poplar (Ruttink et al. 2007).

Interestingly, the statistically significant differences in gene expression between "Royal Gala" and "Castel Gala" for the 17 genes were concentrated at some sampling points, namely May and July 2009, and February 2010. Because it is known that "Castel Gala" buds flush more than 1 month earlier than "Gala Standard" or "Royal Gala" buds (Denardi and Seccon 2005; Anzanello 2012), it could be suggested that the entire "Castel Gala" cycle is anticipated and that the differential gene expression observed is the result of the developmental time shift between cultivars. However, at least for the genes tested, the steady-state mRNA levels that differed in the three sampling points do not provide enough support for a consistent differential expression derived only from a developmental time shift. This suggests that the molecular mechanisms responsible for "Gala Standard" or "Royal Gala" and "Castel Gala" phenological differences act episodically (Fig. 4; Fig. S2).

In the model plant $A$. thaliana, a set of cold-regulated genes is responsive to the CBF/DREB1 transcription factors (Thomashow 2010). The concerted action of these proteins regulates the expression of cold-related (COR) genes, which confer cold-tolerance (Kurbidaeva and Novokreshchenova 2011). In our work, several genes that putatively participate in the $C B F / D R E B 1$ pathway were identified and validated, such as CAMTA1 (ABD9), DHNs (ABD11, ABD12 and $A B D 13)$, GolS (ABD15) and ICE1 (ABD19).

$A$. thaliana DHNs are a type of $C O R$ genes, with wellcharacterized roles in dehydration-related stresses, protecting membranes and proteins (Kosová et al. 2007). In temperate woody species, dormant buds reduce their free water content and DHN proteins are known to accumulate during the winter (Faust et al. 1997; Erez et al. 1998). In our SSH studies, we identified three $D H N$ genes, which were recently identified, cloned and characterized in apple (Liang et al. 2012). ABD11 was highly expressed in dormant buds and was also described as midwinter-expressed (Garcia-Bañuelos et al. 2009). Another transcript identified in our study, $A B D 13$, was identified in an EST collection as a cold-responsive gene
(Wisniewski et al. 2008). The remaining gene, $A B D 12$, is presented in our work for the first time as related to bud dormancy, being seasonally controlled and highly influenced by the genotype background (Figs. 4, 5 and 6). The higher transcript accumulation observed for these genes over the winter in all three cultivars (Figs. 4 and 5) suggests that they may be playing important roles during dormancy, as described for DHNs of other perennial tree species such as birch (Welling et al. 2004), Japanese apricot (Yamane et al. 2006), and Norway spruce (Yakolev et al. 2008). In addition, ABD11 displayed a dormancy-dependent transcriptional pattern among the three cultivars analyzed during 2009/2010. Both of the high CR cultivars, "Fuji Standard" and "Royal Gala", which stayed dormant until September, had high transcription levels at least until July 2009. Conversely, "Castel Gala", the low CR cultivar, presented an anticipated sharp decline of transcript levels in July 2009 (winter) immediately prior to growth resumption. Garcia-Bañuelos et al. (2009) have previously suggested the use of this gene as a molecular marker to follow dormancy progression in apple trees. Our data provide additional evidence for the association between $A B D 11$ expression and dormancy progression, reinforcing its potential usefulness for breeding or biotechnological purposes.

In A. thaliana, in addition to genes encoding DHNs, CBF/ DREB1 transcription factors are known to induce the expression of a galactinol synthase gene (AtGolS3; Maruyama et al. 2009). This enzyme participates in the production of galactinol, a building block for the synthesis of raffinic sugars, which accumulate in response to cold, freezing and water deficit (Klotke et al. 2004). In our study, for the first time in apple dormant buds, transcripts for a GolS were found highly enriched in midwinter samples, primarily in "Fuji Standard" buds (Fig. 6 and Figs. S2 and S3). The transcriptional profiles obtained for this gene from all three cultivars suggest midwinter expression (Figs. S2 and S3), as reported in stems of hybrid poplar (Unda et al. 2012), dormant buds of sessile oak (Derory et al. 2006) and chestnut (Santamaría et al. 2011). Our findings, combined with published data, suggest an important adaptive participation of raffinic sugars in bud dormancy progression. Because apple dormant buds contain reduced free water content (Faust et al. 1997), the accumulation of compatible raffinic sugars could be a mechanism to preserve cellular integrity under freezing and water deficit conditions during dormancy.

In addition to genes putatively regulated by $C B F / D R E B 1$, in the $\mathrm{G} 2-\mathrm{K} 2$ subtraction we identified two transcripts ( $A B D 9$ and $A B D 19$ ) that potentially encode proteins upstream in the signal transduction cascade. In $A$. thaliana, these genes encode trans-acting proteins that transduce cold signals (Kurbidaeva and Novokreshchenova 2011). To our knowledge, this is the first time that CAMTA1 has been identified in a dormancy-related study, although the differential expression of genes similar to ICE1 during dormancy have been 
reported for at least two other plants (Horvath et al. 2008; Leida et al. 2010). More recently, a putative ICE1 ortholog from apple was characterized (Feng et al. 2012), but the EST cloned in our study was not derived from the same predicted gene model. Higher expression levels of $A B D 9$ and $A B D 19$ were expected for "Royal Gala" in relation to "Castel Gala" in July 2009, as observed for "Gala Standard" during the winter (Fig. 3). However, this profile was not confirmed (Fig. 6; Fig.S2). In fact, no clear relationship of transcript accumulation for these genes between the high CR cultivars was observed in the 2009/2010 samples (Fig. 6; Figs. S2 and S3). Because the transcription of AtCAMTA genes has been reported to be responsive to various elicitors and abiotic stresses (Yang and Poovalah 2002), the RT-qPCR data derived from the 2009 samples for this gene may result from some source of regulation not related to those affecting previous samplings. Furthermore, other levels of regulation may account for modulation of gene product activity. For example, posttranslational modifications of ICE1 are triggered by cold exposure (Miura et al. 2007; Feng et al. 2012). The data suggest the participation of the $C B F / D R E B 1$ regulon during the maintenance of the apple bud dormant state (Horvath 2009; Wisniewski et al. 2011).

Gibberellin signaling is important for dormancy progression. Ectopic application of active gibberellins was shown to substitute for chilling exposure (Hartmann et al. 2011; van der Schoot and Rinne 2011). Recently, a study provided a mechanistic view of dormancy release as the reestablishment of symplastic connections by gibberellin-induced degradation of plasmodesmal callose (Rinne et al. 2011). In our work, at least three genes potentially related to gibberellin signaling, GAST1 (ABD16), GRAS (ABD17) and SCL (ABD18), were enriched in dormant buds. $A B D 16$ showed a striking contrast in expression level between "Royal Gala" and "Castel Gala" buds in May and July 2009 (Fig. 4), as well as between summer and winter samples of both high CR cultivars (Figs. 4, 5 and 6). A putative GAST1 homolog has been described as enriched in dormant buds of leafy spurge (Dogramaci et al. 2010). Although the exact function of GAST1 is unknown, its reported responsiveness to gibberellins suggests its involvement in the signaling of this hormone class during bud dormancy (Shi et al. 1992; Raventos et al. 2000).

The GRAS protein family and its SCL members are transcription factors involved in global functions such as growth, development, gibberellin signaling and light signal transduction (Lee et al. 2008). In our study, transcripts potentially coding for GRAS and SCL-like proteins were identified and validated in 2007 and 2008 as enriched in the G2-K2 library (Fig. 3). The same pattern of transcript accumulation was not observed in the 2009 samples (Fig. S2). However, RT-qPCR analysis allowed us to detect significantly higher expression levels of both genes in "Gala Standard" and "Royal Gala" in late autumn (May) samples throughout the three years of sampling (Fig. 3 and Fig. S2). $A B D 17$ is very similar to the PHYTOCHROME A SIGNAL TRANSDUCTION gene from A. thaliana, which is involved in far-red light signaling (Bolle et al. 2000). A gene with the same annotation was identified in peach trees by SSH when comparing dormant buds with dormancy-released buds from a high CR cultivar, as well as comparing dormancy-released buds from high CR to low CR cultivars (Leida et al. 2010).

$D A M$ genes were first described by the characterization of the ever-growing mutant of peach (Prunus persica (L.) Batsch), which does not enter into dormancy even under arrest-inducing conditions (Bielenberg et al. 2008). This cultivar has a 41,746 bp deletion at the $E V G$ locus of chromosome 1, affecting a cluster of six StMADS11-clade MADSbox genes and impairing the expression of four of them. Of these six genes, PpDAM5 and PpDAM6 were shown to have expression patterns in buds consistent with a growthrepressing role, increasing during autumn and declining through the winter ( $\mathrm{Li}$ et al. 2009; Yamane et al. 2011). Similar genes were found in pear (Ubi et al. 2010), leafy spurge (Horvath et al. 2010), Japanese apricot (Sasaki et al. 2011) and kiwifruit (Wu et al. 2012), but to date, no DAM gene orthologs have been characterized in apple.

"Gala Standard" buds revealed the accumulation of transcripts derived from a $D A M$-like $(A B D 14)$ gene with high levels of expression during the winter (Fig. 3). This gene displayed a dormancy-related expression pattern in all three cultivars analyzed throughout the 2009/2010 cycle, with its transcript accumulation strongly decreasing in the summer in a very similar fashion to peach $P p D A M 5$ and $P p D A M 6$ genes (Figs. 4, 5 and 6; Li et al. 2009; Yamane et al. 2011). Moreover, ABD14 transcript accumulation decreased earlier in the low CR cultivar Castel Gala than in the high CR cultivars Royal Gala and Fuji Standard. This result is similar to that reported by Sasaki et al. (2011) for the Prunus mume $D A M$ orthologs PmDAM3, PmDAM4, PmDAM5 and PmDAM6 and by Yamane et al. (2011) for peach PpDAM5 and $P p D A M 6$. In an independent approach, our group identified six putative $D A M$ genes by in silico analyses exploring the Malus $\times$ domestica predicted gene models (Velasco et al. 2010). Four of them showed seasonal- and cold-regulated transcriptional profiles, including the one found in the present study (Porto et al. manuscript in preparation). Finally, because peach and apple are evolutionarily close (Illa et al. 2011), it is tempting to speculate that the $D A M$-like gene described here participates in dormancy establishment in apples analogously to $P p D A M$ genes.

In addition to the putative $D A M$ gene, at least two other transcripts potentially coding for transcription factors were found enriched in the G2-K2 subtraction, namely a NAC (ABD21) and an AP2 (ABD8) domain-containing protein. Transcripts coding for similar transcription factors were found in dormant buds of peach by SSH (Leida et al. 2010). ABD21 
showed a profile similar to $A B D 14$ in the 2009/2010 samples, with a decay in transcript accumulation prior to budbreak in the "Castel Gala" and "Fuji Standard" samples (Figs. 4 and 5), suggesting an association with the dormancy process. AP2 was described in Arabidopsis thaliana as a major negative regulator of flowering (Yant et al. 2010) and its identification in the G2-K2 subtraction data suggests participation in dormancy maintenance. Hence, a transcriptional profile for $A B D 8$ similar to the ones observed in 2009/2010 samples for $A B D 14$ and $A B D 21$ genes could be predicted. This profile was only found in "Fuji Standard" samples (Fig. S3). "Castel Gala" and "Royal Gala" samples did not support this hypothesis (Fig. S2) because this clear seasonal pattern could not be observed.

Hypoxic conditions induce alternative methods of respiration (Bailey-Serres et al. 2012). Dormancy breaking of grape buds by hydrogen cyanamide or heat shock application induces the expression of a range of hypoxia-related genes such as those coding for $\mathrm{ADH}$ and pyruvate decarboxylase for a short period of 4 days (Or et al. 2000; Ophir et al. 2009). In peach, an $A D H$ gene was associated with dormancy release by SSH (Leida et al. 2010). We identified a transcript putatively coding for ADH (ABD7) with an opposite pattern of mRNA accumulation to these findings in the 2007 and 2008 samples (Fig. 3). In 2009, ABD7 steady-state mRNA levels did not show clear seasonal variation in the three cultivars (Figs. S2 and S3). Our sampling strategy may not have represented the short interval in which the peak of $A B D 7$ expression related to budbreak occurs (Or et al. 2000; Pacey-Miller et al. 2003).

Recently, a key transcription factor in hypoxia signaling, RAP2.12, was described in $A$. thaliana. It directly senses low oxygen concentrations and induces the expression of hypoxiarelated genes (Licausi et al. 2011). A unigene (ABD1) very similar (62.2\%) to RAP2.12 was identified in the G1-K1 subtraction and is recurrently more highly expressed in "Gala Standard" and "Royal Gala" than in "Castel Gala" during the autumn (Figs. 3 and 4). The higher transcript accumulation of $A B D 1$ in "Castel Gala" buds during the winter (Fig. 4) suggests enhanced hypoxia-related gene expression near budbreak, similar to observations in grapes (Or et al. 2000; Ophir et al. 2009).

Histones are central players in cell division and DNA metabolism. Some histone variants may have roles in transcriptional control, such as H2A.Z, which regulates gene expression according to ambient temperature (Kumar and Wigge 2010). The SSH K2-G2 subtraction allowed us to identify many ESTs and unigenes matching histones. We further investigated transcripts matching an A. thaliana canonical H2A (AtHTA12;ABD28) and an H2A.Z variant (AtHTA8; ABD5). ABD5 and ABD28 were more highly expressed in "Castel Gala" and "Fuji Standard" buds close to budburst, in agreement with their function in cell division and growth (Figs. 4 and 5). In A. thaliana, the H2A.Z variant
AtHTA 8 was slightly more expressed during the $\mathrm{S}$ phase of the cell cycle (March-Díaz and Reyes 2009), and canonical H2A AtHTA12 is also cell cycle regulated (Yi et al. 2006). Although these genes belong to distinct histone groups in A. thaliana, a similar expression pattern was observed in our data, with a higher scale of induction for $A B D 28$. Dormancy release also involves the induction of histone transcripts in raspberry (Mazzitelli et al. 2007) and in grape (Mathiason et al. 2009).

Finally, we validated and analyzed the transcript accumulation for the putative apple LTI65 gene (ABD4), which still does not have a clearly described function. Transcription of the $A$. thaliana AtLTI65 gene (also known as AtRD29B) was highly induced in response to abiotic stress (Msanne et al. 2011). However, contrary to the expectation, knockout mutants were more stresstolerant than the wild-type. These data suggested that the protein encoded by AtLTI65 does not directly protect cells (Msanne et al. 2011). In our study, the variation in transcript abundance observed for this gene throughout 2009/2010 is remarkable (Figs. 4 and 5), mainly during winter in the "Fuji Standard" genetic background (Fig. 5). The seasonal transcription profiles for $A B D 4$ in the three cultivars analyzed nearly overlapped, suggesting an environmental control of expression. Close homologs for AtLTI65 were not reported for relevant crop species (Msanne et al. 2011).

The identification of differential gene expression related to CR may be a useful tool for accelerating the breeding of new cultivars. In this sense, at least two other studies have measured mRNA levels to separate high- from low-CR cultivars (Yooyongwech et al. 2009; Leida et al. 2012). As reported by Yooyongwech et al. (2009), the expression of two aquaporins could be used to indicate the state of dormancy release in peach buds. Leida et al. (2012) analyzed five genes and found correlations between gene expression and the CR measurements performed by Utah and Dynamic models. We analyzed gene expression of the 17 validated genes in three distinct CR cultivars to assess genotype-related differences of this trait. Interestingly, two genes displayed significant differences between high- and low-CR cultivars, namely $A B D 14$ and $A B D 28$ (Fig. 6). While the first transcript was more expressed in both high CR cultivars, the second transcript was more expressed in the low CR cultivar. More studies are needed to confirm these relationships, but these results strongly suggest that in the future an efficient method to analyze distinct CR cultivars by gene expression could be implemented.

In conclusion, the transcriptional profiles obtained for several genes during the 2009/2010 cycle allow us to suggest that down-regulation of genes associated with dormancy maintenance, as well as up-regulation of genes associated with dormancy release, are anticipated in "Castel Gala". Most of these genes displayed a markedly seasonal expression profile in a close relationship with the winter period. Seventeen genes belonging to a broad range of functions were identified as differentially expressed in apple buds from the different $\mathrm{CR}$ 
cultivars. The unigenes annotated as CAMTA1, HTA8, RAP2.12 and LTI65 were identified in this study as related to dormancy for the first time, while the other transcripts had similar counterparts in previously described gene expression studies of dormancy progression in other species (Derory et al. 2006; Horvath et al. 2008; Yamane et al. 2008; Leida et al. 2010). Of these 17 candidates, the DAM, DHNs, GAST1, HTA8, HTA12, LTI65, NAC and RAP2.12 genes presented the most consistent differential expression profiles over cultivars and seasons, which confirm their potential role as participants in dormancy regulation. To the best of our knowledge, this work is the first to describe genes that are differentially expressed in the main stages of bud dormancy progression in apple. Our findings provide additional support reinforcing the existence of putative common pathways (e.g., DAM family and gibberellin signaling) involved in dormancy progression, as observed in other temperate species (Horvath 2009; van der Schoot and Rinne 2011). In addition to confirming the relevance of the SSH-selected genes during dormancy progression, the next step will be the functional characterization of the $D A M$ gene family and encoded proteins and their involvement in dormancy control in apple buds.

Acknowledgments We gratefully acknowledge our colleagues at the Laboratory of Plant Molecular Genetics (especially to M.Sc. Pâmela Perini and Ms. Marcela Czarnobay) and Laboratory of Plant Physiology at Embrapa Grape and Wine who helped us in many technical steps. We thank M.Sc. Rochele P. Kirch and Mrs. Jordana B. Ludwig (ACTGene $\mathrm{Lab}$ ) for their technical assistance in DNA sequencing. We also thank "Empresa de Pesquisa Agropecuária do Estado de Santa Catarina" (EPAGRI, Caçador, SC, Brazil, especially to M.Sc. Frederico Denardi and Dr. Marcus V. Kvitschal), Mr. Décio Amorim (Papanduva, SC, Brazil) and Mr. Jânio Seccon (Monte Castelo, SC, Brazil) for providing us with the access to their apple orchards. This work was supported by "Financiadora de Estudos e Projetos" (FINEP, Brazil) [grant number 0107009700] and "Empresa Brasileira de Pesquisa Agropecuária" (Embrapa, Brazil) [grant number 0207070070003]. VSF received a M.Sc. scholarship from "Coordenação de Aperfeiçoamento de Pessoal de Nível Superior" (CAPES, Ministry of Education, Brazil). DDP received a postdoctoral scholarship from "Conselho Nacional de Desenvolvimento Científico e Tecnológico" (CNPq, Ministry of Science and Technology, Brazil). GP and MPM are recipients of research fellowships from CNPq [grant numbers 311361/2009-9 and 306945/2009-6].

\section{References}

Altschul SF, Gish W, Miller W, Myers EW, Lipman DJ (1990) Basic local alignment search tool. J Mol Biol 215:403-410

Anzanello R (2012) Fisiologia e modelagem da dormência em gemas de macieira. Doctoral thesis, Federal University of Rio Grande do Sul, Porto Alegre

Arora R, Rowland LJ, Tanino K (2003) Induction and release of bud dormancy in woody perennials: a science comes of age. Hortscience 38:911-921

Bailey-Serres J, Fukao T, Gibbs DJ, Holdsworth MJ, Lee SC, Licausi F et al (2012) Making sense of low oxygen sensing. Trends in Plant Sci 17:129-138
Bielenberg DG, Wang YE, Li Z, Zhebentyayeva T, Fan S, Reighard GL et al (2008) Sequencing and annotation of the evergrowing locus in peach [Prunus persica (L.) Batsch] reveals a cluster of six MADSbox transcription factors as candidate genes for regulation of terminal bud formation. Tree Genet Genomes 4:495-507

Böhlenius H, Huang T, Charbonnel-Campaa LC, Brunner AM, Jansson $\mathrm{S}$, Strauss SH et al (2006) CO/FT regulatory module controls timing of flowering and seasonal growth cessation in trees. Science 312: 1040-1043

Bolle C, Koncz C, Chua NH (2000) PAT1, a new member of the GRAS family is involved in phytochrome A signal transduction. Genes Dev 14:1269-1278

Botelho RV, Ayub RA, Muller MML (2006) Sommatory of chilling hours and chilling units at different regions of Paraná state. Sci Agr 7:89 96

Campoy JA, Ruiz D, Egea J (2011) Dormancy in temperate fruit trees in a global warming context: A review. Sci Hort 130:357-372

Celton J-M, Martinez S, Jammes M-J, Bechti A, Salvi S, Legave J-M et al (2011) Deciphering the genetic determinism of bud phenology in apple progenies: a new insight into chilling and heat requirement effects on flowering dates and positional candidate genes. New Phytol 192:378-392

Conesa A, Götz S, García-Gómez JM, Terol J, Talón M, Robles M (2005) Blast2GO: a universal tool for annotation, visualization and analysis in functional genomics research. Bioinformatics 21:3674-3676

Denardi F, Seccon JJ (2005) 'Castel Gala' - mutação da macieira 'Gala' com baixa necessidade de frio e maturação precoce. Agropec Catar 18:78-82

Dennis FG (1987) Two methods for studying rest: temperature alternation and genetic analysis. Hortscience 22:820-824

Derory J, Léger P, Garcia V, Schaeffer J, Hauser M, Salin F et al (2006) Transcriptome analysis of bud burst in sessile oak (Quercus petraea). New Phytol 170:723-738

Dogramaci M, Horvath DP, Chao WS, Foley ME, Christoffers MJ, Anderson JV (2010) Low temperatures impact dormancy status, flowering competence, and transcript profiles in crown buds of leafy spurge. Plant Mol Biol 73:207-226

EPAGRI (2006) Cultivares: descrição e comportamento no sul do Brasil. In A cultura da macieira. Gráfica Editora Pallotti, Florianópolis, pp $113-132$

EPPO (1984) EPPO crop growth stage keys. EPPO Bull 14:291-294

Erez A, Faust M, Line MJ (1998) Changes in water status in peach buds on induction, development and release from dormancy. Sci Hortic 73:111-123

Faust M, Erez A, Rowland LJ, Wang SY, Norman HA (1997) Bud dormancy in perennial fruit trees: physiological basis for dormancy induction, maintenance and release. Hortscience 32:623-629

Feng X, Zhao Q, Zhao L, Qiao Y, Xie X, Li H et al (2012) The coldinduced basic helix-loop-helix transcription factor gene MdCIbHLH1 encodes an ICE-like protein in apple. BMC Plant Biol 12:22

Fernie AR, Tadmor Y, Zamir D (2006) Natural genetic variation for improving crop quality. Curr Op Plant Biol 9:196-202

Garcia-Bañuelos ML, Gardea AA, Winzerling JJ, Moreno LV (2009) Characterization of a midwinter-expressed dehydrin (DHN) gene from apple trees (Malus domestica). Plant Mol Biol Rep 27:476487

Hartmann A, Senning M, Hedden P, Sonnewald U, Sonnewald S (2011) Reactivation of meristem activity and sprout growth in potato tubers require both cytokinin and gibberellin. Plant Physiol 155:776-796

He JX, Fujioka S, Li TC, Kang SG, Seto H, Takatsuto S et al (2003) Sterols regulate development and gene expression in Arabidopsis. Plant Physiol 131:1258-1269

Heide OM, Prestrud AK (2005) Low temperature, but not photoperiod, controls growth cessation and dormancy induction and release in apple and pear. Tree Physiol 25:109-114 
Horvath D (2009) Common mechanisms regulate flowering and dormancy. Plant Sci 177:523-531

Horvath DP, Anderson JV, Chao WS, Foley ME (2003) Knowing when to grow: signals regulating bud dormancy. Trends Plant Sci 8:534-540

Horvath DP, Chao WS, Suttle JC, Thimmapuram J, Anderson JV (2008) Transcriptome analysis identifies novel responses and potential regulatory genes involved in seasonal dormancy transitions of leafy spurge (Euphorbia esula L.). BMC Genomics 9:536

Horvath DP, Sung S, Kim D, Chao W, Anderson J (2010) Characterization, expression and function of DORMANCY ASSOCIATED MADS-BOX genes from leafy spurge. Plant Mol Biol 73:169-179

Howe GT, Saruup P, Davies J, Chen THH (2000) Quantitative genetics of bud phenology, frost damage and winter survival in an F2 family of hybrid poplars. Theor Appl Genet 101:632-642

Illa E, Sargent DJ, Girona EL, Bushakra J, Cestaro A, Crowhurst R et al (2011) Comparative analysis of rosaceous genomes and the reconstruction of a putative ancestral genome for the family. BMC Evol Biol 11:9

Klotke J, Kopka J, Gatzke N, Heyer AG (2004) Impact of soluble sugar concentrations on the acquisition of freezing tolerance in accessions of Arabidopsis thaliana with contrasting cold adaptation - evidence for a role of raffinose in cold acclimation. Plant Cell Environ 27: $1395-1404$

Kosová K, Vítámvás P, Prášil IT (2007) The role of dehydrins in plant response to cold. Biol Plantarum 51:601-617

Krishnaraj T, Gajjeraman P, Palanisamy S, Chandrabose SRS, Mandal AKA (2011) Identification of differentially expressed genes in dormant (banjhi) bud of tea (Camellia sinensis (L.) O. Kuntze) using subtractive hybridization approach. Plant Physiol Biochem 49:565571

Kuhn E (2001) From library screening to microarray technology: strategies to determine gene expression profiles and to identify differentially regulated genes in plants. Ann Bot 87:139-155

Kumar SV, Wigge PA (2010) H2A.Z-containing nucleosomes mediate the thermosensory response in Arabidopsis. Cell 140:136-147

Kurbidaeva AS, Novokreshchenova MG (2011) Genetic control of plant resistance to cold. Russ J Genet 47:646-661

Labuschagné IF, Louw JH, Schmidt K, Sadie A (2002) Genetic variation in chilling requirement in apple progeny. J Am Soc Hort Sci 127: 663-672

Lang GA, Early JD, Martin GC, Darnell RL (1987) Endodormancy, paradormancy, and ecodormancy - physiological terminology and classification for dormancy research. Hortscience 22:371-377

Lee MH, Kim B, Song S-K, Heo J-O, Yu N-I Lee SA et al (2008) Largescale analysis of the GRAS gene family in Arabidopsis thaliana. Plant Mol Biol 67:659-670

Leida C, Terol J, Martí G, Agustí M, Llácer G, Badenes ML et al (2010) Identification of genes associated with dormancy release in Prunus persica by suppression subtractive hybridization. Tree Physiol 30: 655-666

Leida C, Romeu JF, García-Brunton J, Ríos G, Badenes ML (2012) Gene expression analysis of chilling requirements for flower bud break in peach. Plant Breed 131:329-334

Li Z, Reighard GL, Abbott AG, Bielenberg BG (2009) Dormancyassociated MADS genes from the EVG locus of peach [Prunus persica (L.) Batsch] have distinct seasonal and photoperiodic expression patterns. J Exp Bot 60:3521-3530

Liang D, Xia H, Wu S, Ma F (2012) Genome-wide identification and expression profiling of dehydrin gene family in Malus domestica. Mol Biol Rep 39:10759-10768

Licausi F, Kosmacz M, Weits DA, Giuntoli B, Giorgi F, Voesenek LACJ et al (2011) Oxygen sensing in plants is mediated by an N-end rule pathway for protein destabilization. Nature 479:419-422

March-Díaz R, Reyes JC (2009) The beauty of being a variant: H2A.Z and the SWR1 complex in plants. Mol Plant 2:565-577
Maruyama K, Takeda M, Kidokoro S, Yamada K, Sakuma Y, Urano K et al (2009) Metabolic pathways involved in cold acclimation identified by integrated analysis of metabolites and transcripts regulated by DREB1A and DREB2A1. Plant Physiol 150:1972-1980

Mathiason K, He D, Grimplet J, Venkateswari J, Galbraith DW, Or E, Fennell A (2009) Transcript profiling in Vitis riparia during chilling requirement fulfillment reveals coordination of gene expression patterns with optimized bud break. Funct Integr Genomics 9:81-96

Mazzitelli L, Hancock RD, Haupt S, Walker PG, Pont SDA, McNicol J et al (2007) Co-ordinated gene expression during phases of dormancy release in raspberry (Rubus idaeus L.) buds. J Exp Bot 58:10351045

Miura K, Jin JB, Lee J, Yoo CY, Stirm V, Miura T et al (2007) SIZ1Mediated sumoylation of ICE1 controls CBF3/DREB1A expression and freezing tolerance in Arabidopsis. Plant Cell 19:1403-1414

Msanne J, Lin J, Stone JM, Awada T (2011) Characterization of abiotic stress-responsive Arabidopsis thaliana RD29A and RD29B genes and evaluation of transgenes. Planta 234:97-107

Newcomb RD, Crowhurst RN, Gleave AP, Rikkerink EH, Allan AC, Beuning LL et al (2006) Analyses of expressed sequence tags from apple. Plant Physiol 141:147-166

Ophir R, Pang X, Halaly T, Venkateswari J, Lavee S, Galbraith D et al (2009) Gene-expression profiling of grape bud response to two alternative dormancy-release stimuli expose possible links between impaired mitochondrial activity, hypoxia, ethylene-ABA interplay and cell enlargement. Plant Mol Biol 71:403-423

Or E, Vilozny I, Eyal Y, Ogrodovitch A (2000) The transduction of the signal for grape bud dormancy breaking induced by hydrogen cyanamide may involve the SNF-like protein kinase GDBRPK. Plant Mol Biol 43:483-494

Pacey-Miller T, Scott K, Ablett E, Tingey S, Ching A, Henry R (2003) Genes associated with the end of dormancy in grapes. Funct Integr Genomics 3:144-152

Penna S (2003) Building stress tolerance through over-producing trehalose in transgenic plants. Trends Plant Sci 8:355-357

Petri JL, Hawerroth FJ, Leite GB, Couto M, Francescatto P (2012) Apple phenology in subtropical climate conditions. In: Zhang X (ed) Phenology and climate change, 1st edn. InTech, doi: 10.5772/34301

Pfaffl MW (2001) A new mathematical model for relative quantification in real-time RT-PCR. Nucl Acids Res 29:2002-2007

Pichler FB, Walton EF, Davy M, Triggs C, Janssen B, Wünsche JN et al (2007) Relative developmental, environmental, and tree-to-tree variability in buds from field-grown apple trees. Tree Genet Genomes 3:329-339

Raventos D, Meier C, Mattsson O, Jensen AB, Mundy J (2000) Fusion genetic analysis of gibberellin signaling mutants. Plant J 22:427438

Rinne PLH, Welling A, Vahala J, Ripel L, Ruonala R, Kangasjarvi J et al (2011) Chilling of dormant buds hyperinduces FLOWERING LOCUS $\mathrm{T}$ and recruits GA-inducible 1,3-b-glucanases to reopen signal conduits and release dormancy in Populus. Plant Cell 23:130 146

Rohde A, Bhalerao RP (2007) Plant dormancy in the perennial context. Trends Plant Sci 12:217-223

Rozen S, Skaletsky HJ (2000) Primer3 on the WWW for general users and for biologist programmers. In: Krawetz S, Misener S (eds) Bioinformatics methods and protocols: methods in molecular biology. Humana Press, Totowa, pp 365-386

Ruonala R, Rinne PLH, Baghour M, Moritz T, Tuominen H, Kangasjärvi $\mathrm{J}$ (2006) Transitions in the functioning of the shoot apical meristem in birch (Betula pendula) involve ethylene. Plant J 46:628-640

Ruttink T, Arend M, Morreel K, Storme V, Rombauts S, Fromm J et al (2007) A molecular timetable for apical bud formation and dormancy induction in poplar. Plant Cell 19:2370-2390

Santamaría ME, Rodríguez R, Cañal MJ, Toorop PE (2011) Transcriptome analysis of chestnut (Castanea sativa) tree buds 
suggests a putative role for epigenetic control of bud dormancy. Ann Bot 108:485-498

Sasaki R, Yamane H, Ooka T, Jotatsu H, Kitamura Y, Akagi T et al (2011) Functional and expressional analysis of PmDAM genes associated with endodormancy in Japanese apricot. Plant Physiol 157:485-497

Shi L, Gast RT, Gopalraj M, Olszewski NE (1992) Characterization of a shoot-specific, $\mathrm{GA}_{3}$ - and ABA-regulated gene from tomato. Plant J 2:153-159

Taji T, Ohsumi C, Iuchi S, Seki M, Kasuga M, Kobayashi M (2002) Important roles of drought- and cold-inducible genes for galactinol synthase in stress tolerance in Arabidopsis thaliana. Plant J 29:417426

Thomashow MF (2010) Molecular basis of plant cold acclimation: insights gained from studying the CBF cold response pathway. Plant Physiol 154:571-577

Troggio M, Gleave A, Salvi S, Chagné D, Cestaro A, Kumar S et al (2012) Apple, from genome to breeding. Tree Genet Genomes 8: 509-529

Ubi BE, Ban Y, Shimada T, Ito A, Nakajima I, Takemura Y et al (2010) Molecular cloning of dormancy-associated mads-box gene homologs and their characterization during seasonal endodormancy transitional phases of Japanese pear. J Am Soc Hortic Sci 135:174-182

Unda F, Canam T, Preston L, Mansfield SD (2012) Isolation and characterization of galactinol synthases from hybrid poplar. J Exp Bot 63: 2059-2069

van der Schoot C, Rinne PLH (2011) Dormancy cycling at the shoot apical meristem: Transitioning between self-organization and selfarrest. Plant Sci 180:120-131

van Dyk MM, Soeker MK, Labuschagne IF, Rees DJG (2010) Identification of a major QTL for time of initial vegetative budbreak in apple (Malus $\times$ domestica Borkh.). Tree Genet Genomes 6:489_ 502

Velasco R, Zharkikh A, Affourtit J, Dhingra A, Cestaro A, Kalyanaraman $A$ et al (2010) The genome of the domesticated apple (Malus $\times$ domestica Borkh.). Nat Genet 42:833-839

Walsh CS, Volz R (1990) 'Gala', and the red 'Gala' sports: a preliminary comparison of fruit maturity. Fruit Varieties J 44:18-23

Welling A, Rinne P, Viherä-Aarnio A, Kontunen-Soppela S, Heino P, Palva ET (2004) Photoperiod and temperature differentially regulate the expression of two dehydrin genes during overwintering of birch (Betula pubescens Ehrh.). J Exp Bot 55:507-516

Wisniewski M, Bassett C, Norelli J, Macarisin D, Artlip T, Gasic K et al (2008) Expressed sequence tag analysis of the response of apple
(Malus $\times$ domestica 'Royal Gala') to low temperature and water deficit. Physiol Plantarum 133:298-317

Wisniewski M, Norelli J, Bassett C, Artlip T, Macarisin D (2011) Ectopic expression of a novel peach (Prunus persica) CBF transcription factor in apple (Malus $\times$ domestica) results in short-day induced dormancy and increased cold hardiness. Planta 233:971-983

Wu R, Walton EF, Richardson AC, Wood M, Hellens RP, Varkonyi-Gasic E (2012) Conservation and divergence of four kiwifruit SVP-like MADS-box genes suggest distinct roles in kiwifruit bud dormancy and flowering. J Exp Bot 63:797-807

Yakolev IA, Asante DAK, Fossdal CG, Partanen J, Junttila O, Johnsen Ø (2008) Dehydrins expression related to timing of bud burst in Norway spruce. Planta 228:459-472

Yamane H, Kashiwa Y, Kakehi E, Yionemori K, Mori H, Hayashi K et al (2006) Differential expression of dehydrin in flower buds of two Japanese apricot cultivars requiring different chilling requirements for bud break. Tree Physiol 26:1559-1563

Yamane H, Kashiwa Y, Ooka T, Tao R, Yionemori K (2008) Suppression subtractive hybridization in differential screening reveals endodormancy-associated expression of an SVP/AGL24-type MADS-box gene in lateral vegetative buds of Japanese apricot. J Am Soc Hort Sci 133:708-716

Yamane H, Ooka T, Jotatsu H, Sasaki R, Tao R (2011) Expression analysis of PpDAM5 and PpDAM6 during flower bud development in peach (Prunus persica). Sci Hortic 129:844-848

Yang T, Poovalah BW (2002) A calmodulin-binding/CGCG box DNAbinding protein family involved in multiple signaling pathways in plants. J Biol Chem 277:45049-45058

Yant L, Mathieu J, Dihn TT, Ott F, Lanz C, Wollmann H et al (2010) Orchestration of the floral transition and floral development in Arabidopsis by the bifunctional transcription factor APETALA2. Plant Cell 22:2156-2170

Yi H, Sardesai N, Fujinuma T, Chan C, Veena GSB (2006) Constitutive expression exposes functional redundancy between the Arabidopsis histone $\mathrm{H} 2 \mathrm{~A}$ gene HTA1 and other $\mathrm{H} 2 \mathrm{~A}$ gene family members. Plant Cell 18:1575-1589

Yooyongwech S, Sugaya S, Sekozawa Y, Gemma H (2009) Differential adaptation of high- and low-chill dormant peaches in winter through aquaporin gene expression and soluble sugar content. Plant Cell Rep 28:1709-1715

Zeng Y, Yang T (2002) RNA isolation from highly viscous samples rich in polyphenols and polysaccharides. Plant Mol Biol Rep 20:417a$417 \mathrm{e}$ 